\title{
Duzhong Fang Attenuates the POMC-Derived Neuroinflammation in Parkinsonian Mice
}

\author{
Lili Li ${ }^{1, *}$ \\ Shanshan Fan ${ }^{1} *$ \\ Wenqi Zhang' \\ Dongna $\mathrm{Li}^{\mathrm{I}}$ \\ Zhen Yang ${ }^{1,2}$ \\ Pengwei Zhuang ${ }^{1,2}$ \\ Juan $\mathrm{Han}^{3}$ \\ Hong Guo' \\ Yanjun Zhang' \\ 'State Key Laboratory of Component- \\ based Chinese Medicine, Tianjin \\ University of Traditional Chinese \\ Medicine, Tianjin, 3016I7, People's \\ Republic of China; ${ }^{2}$ School of Chinese \\ Materia Medica, Tianjin University of \\ Traditional Chinese Medicine, Tianjin, \\ 3016I7, People's Republic of China; \\ ${ }^{3}$ College of Traditional Chinese Medicine, \\ Tianjin University of Traditional Chinese \\ Medicine, Tianjin, 301617, People's \\ Republic of China \\ *These authors contributed equally to \\ this work
}

Correspondence: Hong Guo; Yanjun

Zhang

Tianjin University of Traditional Chinese

Medicine, Tianjin, 301617, People's

Republic of China

Email cacti1983@163.com;

zyjsunye@163.com
Background: Neuroinflammation and microglia reactivity are now recognized to be features of Parkinson's disease (PD). Thus, microglia phenotype is a potential new target for developing treatments against PD. Duzhong Fang (DZF) is a traditional Chinese medicine (TCM) prescription. The theory of TCM argues that Duzhong Fang, nourishing yin and tonifying yang, may treat PD. However, its modern pharmacological studies and the underlying mechanisms are unclear.

Methods: First, MPTP was used to establish a parkinsonian mouse model, and behavioral testing was used to evaluate the locomotor dysfunction. Then, HPLC, immunohistochemical staining, and Western blot assays were performed to evaluate the survival of dopaminergic neurons. Molecular biological and immunofluorescence staining were used to evaluate the neuroinflammation and microglial activation. In addition, RNA-seq transcriptomics was used to analyze differentially expressed genes and verify by RT-PCR.

Results: In the present study, we first confirmed that DZF can alleviate neuroinflammation and ameliorate dyskinesia in parkinsonian mice. Then, further studies found that DZF can regulate microglial morphology and reactivity and act on the POMC gene. POMC is an upstream target for regulating inflammation and proinflammatory cytokines, and DZF can directly inhibit the POMC level and restore the homeostatic signature of microglia in parkinsonian mice.

Conclusion: This study found that POMC may have a potential role as a therapeutic target for PD. DZF may inhibit neuroinflammation and play an anti-PD effect by down-regulating the expression of POMC.

Keywords: Parkinson's disease, microglia, inflammation, DZF, POMC

\section{Introduction}

Parkinson's disease (PD) is the second most common progressive neurodegenerative brain disorder in humans, after Alzheimer's disease. In recent years, the incidence of PD has gradually increased, and PD affects $1 \%$ of the population above 60 years old. ${ }^{1}$ The main pathology are $\alpha$-synuclein-containing Lewy bodies and loss of dopaminergic neurons in the substantia nigra pars compacta ( $\mathrm{SNpc}$ ), manifesting as motor symptoms including resting tremor, muscle stiffness, and gait instability. ${ }^{2,3}$ Inflammation is an important factor in the initiation and development of PD. ${ }^{4}$ Patients with PD often exhibit innate immune system activation and increased inflammatory markers, mainly IL- $1 \beta$, IL-6, and TNF- $\alpha .^{5}$

Microglia is a type of glial cells, which are equivalent to macrophages in the brain and spinal cord. They can remove damaged nerves, plaques and infectious substances in the central nervous system, but they can also cause neurotoxicity, 
which in turn triggers a series of inflammatory reaction if they are excessively activated or out of control. ${ }^{6-8}$ Growing evidence shows that microglial reactivity is an early and characteristic feature of $\mathrm{PD},{ }^{9}$ and inhibition of neuroinflammation can be a promising target for the development of the therapeutic strategies for PD.

At present, there are no specific treatments that target neuroinflammation for PD. The epidemiological evidence indicated that a reduced occurrence of PD with persistent use of non-steroidal anti-inflammatory drugs (NSAIDs). ${ }^{10,11}$ Yet, long-term administration can result in severe adverse effects and remains controversial. ${ }^{12,13}$ Traditional Chinese medicine (TCM) has been used as the major therapeutic modalities in China, and gains wide attention worldwide recently. And many traditional Chinese medicines have inhibitory effects on inflammation in neurodegenerative diseases and even neuroinflammation caused by microglia. ${ }^{14-16}$

In traditional Chinese medicine theory, PD is considered to be "fibrillation syndrome", which treatment is based on nourishing yin and tonifying yang. "Yin and Yang" theory, a fundamental concept of TCM, based on the different attributes of body composition. ${ }^{17}$ Duzhong Fang (DZF), is a TCM prescription from "Beiji Qianjin Yao Fang", takes Eucommia ulmoides, supplemented by Dendrobium, Rehmanniae Radix, and Dried Ginger to achieve the effects of replenishing liver and kidney while dispelling cold and nourishing yin. Previously, we found that Eucommia ulmoides can exert antiinflammatory effects by inhibiting the expression of inflammatory cytokines IL- $1 \beta$, TNF- $\alpha$, and IL-6, thereby preventing motor dysfunction in parkinsonian mice. ${ }^{18}$ Therefore, this study builds on the previous results to further uncover the molecular mechanism of DZF on microglial reactivity in parkinsonian mice. Then, combining with transcriptome sequencing to further seek the upstream targets for regulating microglia phenotypic change. Our findings underscore the mechanism that DZF attenuating the POMC gene drives the phenotype of dysfunctional microglia, contributing to the overall control of neuroinflammation in PD.

\section{Materials and Methods}

\section{Reagents}

1-Methyl-4-phenyl-1,2,3,6-tetrahydropyridine (MPTP) and 3,4-Dihydroxyphenylacetic acid (DOPAC) were provided by Sigma-Aldrich (Saint Louis, USA). Dopamine (DA) and Homovanillic acid (HVA) were provided by Solarbio
(Beijing, China). Anti-Tyrosine Hydroxylase antibody was provided by Abcam (Cambridge, UK), anti-MHC class II was provided by Santa Cruz (Dallas, USA), anti-Arginase-1 was purchased from Cell Signaling Technology (Danvers, MA, USA), goat anti-rabbit IgG and goat anti-mouse IgG conjugated to HRP were purchased from Beyotime Institute of Biotechnology (Shanghai, China), and ELISA Kits were provided by R\&D (Minneapolis, USA).

\section{Preparation and Analysis of Duzhong Fang Extract}

Dried Eucommia ulmoides, Dendrobium, Rehmanniae Radix, and Dried Ginger at a ratio of 200:2:3:3 by weight, were refluxed twice in $75 \%$ ethanol (reflux for 2 hours each time), and the refluxed supernatant was collected, filtered and concentrated to obtain Duzhong Fang extract (about $11 \%$ yield). The raw herbs were purchased from Beijing Tongrentang Co., Ltd., China, and botanic origin and storage complied with the Chinese Pharmacopoeia. ${ }^{19}$

Identification of chemical constituents in the DZF extract was performed by UPLC-Q-TOF/MS system. Chromatographic conditions: chromatographic column is Waters Acquity UPLC HSS T3 column $(2.1 \times 100 \mathrm{~mm}, 1.8$ $\mu \mathrm{m}$ ); mobile phase is $0.1 \%$ formic acid in acetonitrile (A)$0.1 \%$ formic acid in water (B); column temperature was $40^{\circ} \mathrm{C}$; sample room temperature was $4^{\circ} \mathrm{C}$; flow rate is $0.3 \mathrm{~mL} / \mathrm{min}$; injection volume was $5 \mu \mathrm{L}$. In negative ion mode, the gradient curve was 0-2 minutes, $5-30 \% \mathrm{~A} ; 2-$ 25 minutes, $30-90 \% \mathrm{~A} ; 25.1-33$ minutes, $5 \% \mathrm{~A}$; in positive ion mode, $0-20$ minutes, $1-80 \% \mathrm{~A} ; 20.1-28$ minutes, $80-1 \%$ A. Mass spectrometry conditions use electrospray ion source (ESI source), positive ion and negative ion two modes to obtain data. The ion source temperature is $120^{\circ} \mathrm{C}$, the capillary voltage was $1.0 \mathrm{kV}$, the cone gas volume flow rate was $50 \mathrm{~L} / \mathrm{h}$, the desolventizing temperature was $300^{\circ} \mathrm{C}$, and the desolventizing gas volume flow rate was $800 \mathrm{~L} / \mathrm{h}$. The cone voltage in the positive ion mode was $20 \mathrm{~V}$, and the cone voltage in the negative ion mode was $50 \mathrm{~V}$. Collected data from 50 to $1200 \mathrm{~m} / \mathrm{z}$. MassLynx $^{\mathrm{TM}} 4.1$ software (Waters Corp., Milford, MA, USA) was used to process the data.

\section{Experimental Design}

Eight-week-old male C57BL/6 mice (18 22 g) were acquired from Beijing Vital River Laboratory Animal Technology Co., Ltd. (Certificate No. SCXK (Jing) 2019-0008). Animals were housed in standard cages for 
one week at $21 \pm 1^{\circ} \mathrm{C}$ on a $12 \mathrm{~h}$ light-dark cycle, with food and water ad libitum. Before sacrifice, all animals were fasted for $12 \mathrm{~h}$, but with free access to water.

All animals were randomly divided into Control, MPTP, MPTP-DZF (MPTP+DZF) and MPTP-S (MPTP + Selegiline) groups according to weight. The MPTPDZF and MPTP-S groups were intragastrically administered to the DZF (10.4 g/ kg/day of DZF crude drug) and selegiline ( $2 \mathrm{mg} / \mathrm{kg} /$ day), respectively, for 8 consecutive days. ${ }^{18}$ The Control and MPTP groups were given an equal volume of distilled water by gavage at the same time. From the 4 th day, mice in the MPTP, MPTP-DZF and MPTP-S groups received intraperitoneal injection with MPTP for 5 consecutive days $(30 \mathrm{mg} / \mathrm{kg} /$ day $){ }^{20}$ In the Control group, an equal volume of saline was injected intraperitoneally at the same time. When preparing and using MPTP, avoid light and pay attention to personal and environmental safety. An equal volume of saline, instead of MPTP, was injected into the Control group. After 3 to 5 minutes of injection, the mice developed tremor, unstable walking, hair stagnation and erection. The schematic diagram of the experimental protocol is shown in Figure 1A.

\section{Ethics Statement}

All studies were performed in accordance with an experimental protocol by the Animal Ethics Committee of Tianjin University of Chinese Medicine (TCMLAEC2019074, Tianjin, China) and the guidelines of the National Institutes for Animal Research.

\section{Behavioral Tests Pole Test ${ }^{21}$}

A vertical pole with a length of about $50 \mathrm{~cm}$ and a diameter of about $1 \mathrm{~cm}$ was prepared, and a plastic ball with a diameter of about $2.5 \mathrm{~cm}$ was fixed to the top of the vertical rod. The vertical rod was wrapped with gauze to prevent slipping. Place the mouse on top of the ball. Record the time it began to crawl down to the landing of the hind limbs. If the mouse pauses or crawls in the middle, it would be re-measured. If it exceeds $60 \mathrm{~s}$, it would be recorded as 60 s. 3 days before the formal experiment, the mice began to conduct behavioral training once a day for 3 consecutive days. One hour after the last dose, the test was formally started and repeated 3 times. The result of the experiment was the average time.
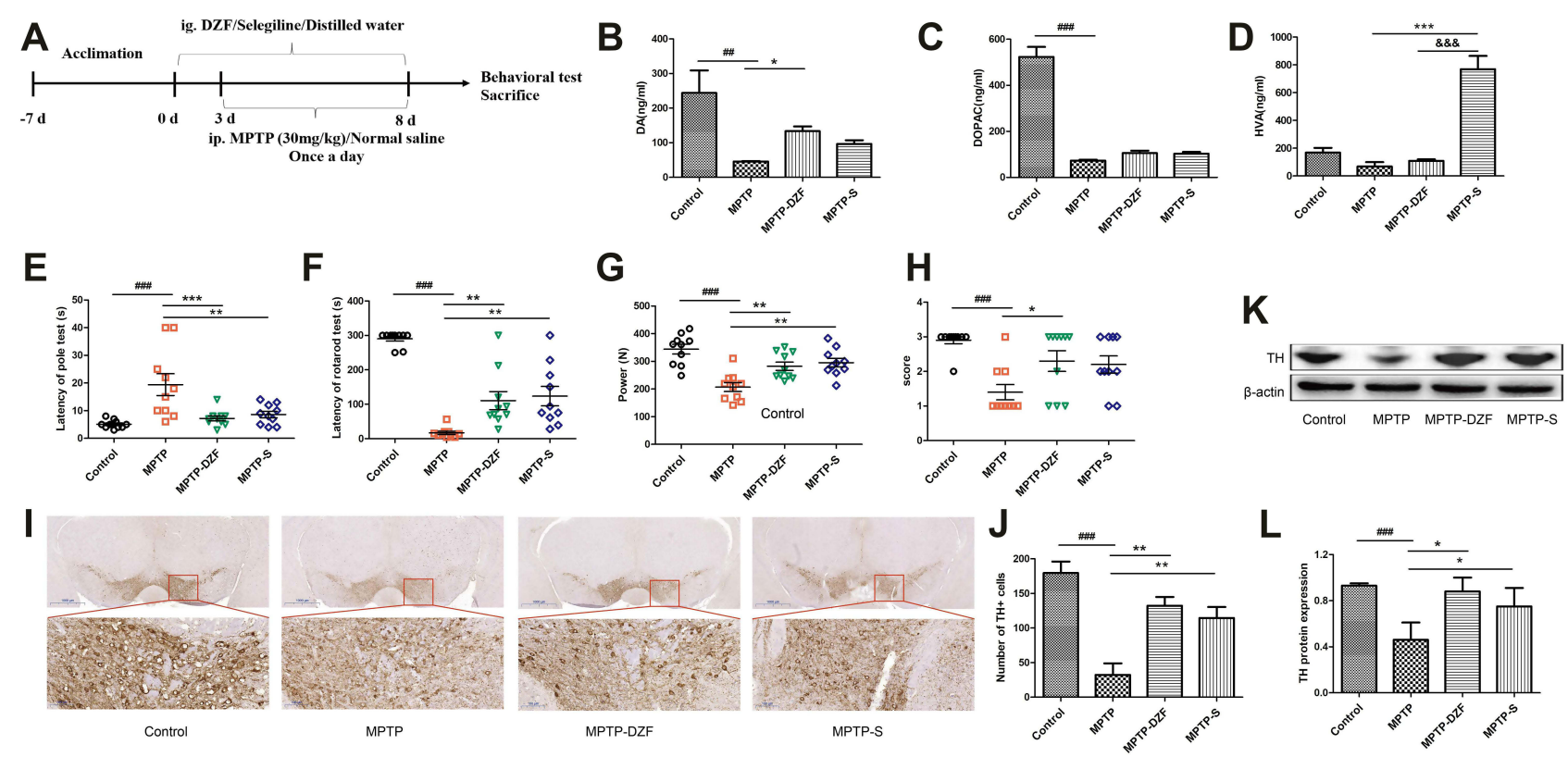

Figure I Neuroprotective effects of DZF on dopaminergic neurons in MPTP-induced parkinsonian mice. (A) The schematic diagram of animal modeling and administration experiment. DZF significantly resulted protected from MPTP induced reductions in (B) DA, but is insensitive to its metabolite (C) DOPAC and (D) HVA. DZF improves MPTP-induced locomotor activity dysfunction including (E) pole, (F) rotarod, (G) grip, and $(\mathbf{H})$ traction test. (I) Immunohistostaining for TH (dopaminergic neuron marker) in the SNpc. (J) Quantitative analysis of the number of TH-positive cells in the SNpc. (K) Representative Western blot of midbrain TH expression. (L) The intensity of bands was quantified with Image J software and quantitative data for TH following normalization to $\beta$-actin. Data represent the means \pm SEM; Statistics one-way ANOVA; ${ }^{\#} P<$ $0.01,{ }^{\# \#} P<0.001$ vs Control group; ${ }^{*} P<0.05$, ${ }^{* *} P<0.01$, ${ }^{* * *} \mathrm{P}<0.00 \mathrm{I}$, vs MPTP group; ${ }^{\& \& \&} \mathrm{P}<0.00 \mathrm{I}$ vs MPTP-DZF group, $\mathrm{n}=10$ for behavioral test and HPLC analysis. $\mathrm{n}=$ 3 for immunohistochemical and Western blotting. 


\section{Rotarod Test ${ }^{22}$}

The mouse was placed on the rotating rod and moved with the rotating rod at a speed of $25 \mathrm{r} / \mathrm{min}$, and the time of the mouse falling was recorded. If the time exceeds $300 \mathrm{~s}$, record $300 \mathrm{~s}$. The mice were trained before the formal experiment. The formal experiment was repeated 3 times with an interval of $5 \mathrm{~min}$ each time, and the average value was calculated.

\section{Grip Strength ${ }^{23}$}

The mouse was placed on the gripper with its body perpendicular to the metal rod on the dynamometer, and the tail was pulled back at a constant speed to measure the grip. Record the reading and repeat three times to calculate the average value.

\section{Traction Test ${ }^{24}$}

The mouse's forelimbs were hung on a horizontal rope, the behavior of the mouse was observed, and the score was calculated. If the mice can grasp the rope with both hind paws, the score is 3 points. If the mice can only use one hind paw to grasp the rope, the score is 2 points. If it cannot grasp the rope with hind limbs, the score is 1 point. The test was performed 3 times for each animal and the average score was taken.

\section{Measurement of DA, DOPAC, and HVA Levels in Mice Striatum by High Performance Liquid Chromatography (HPLC)}

Striatal DA, and its metabolites DOPAC and HVA were quantified by HPLC (Agilent, USA) with electrochemical detection (ECD), following previous methods. ${ }^{15}$ Briefly, 0.1 $\mathrm{M}$ perchloric acid was added to the freshly separated striatum ( $1 \mathrm{mg}: 10 \mu \mathrm{L}$ ), homogenized, and centrifuged at 14,000 rpm for 20 minutes at $4^{\circ} \mathrm{C}$. Then, the supernatants were collected and stored at $-80^{\circ} \mathrm{C}$ until further HPLC analysis.

Chromatographic conditions: C18 column $(3.9 \mathrm{~mm} \times$ $150 \mathrm{~mm}$ ); mobile phase was $19 \%$ methanol, $3 \%$ acetonitrile, $78 \%$ water (containing sodium octyl sulfonate 11.56 $\mathrm{mmol} / \mathrm{L}, \mathrm{NaH}_{2} \mathrm{PO}_{4} 100 \mathrm{~mol} / \mathrm{L}$, EDTA-2Na $0.095 \mathrm{mmol} /$ L). $\mathrm{pH}$ was 3.3-3.4; flow rate was $1 \mathrm{~mL} / \mathrm{min}$; column pressure was 135 bar; injection volume was $10 \mu \mathrm{L}$.

\section{Western Blot Analysis}

The midbrain was placed in a lysis buffer containing protease inhibitors and homogenized by ultrasound on ice, centrifuged at low temperature and the supernatant was collected. BCA quantitative method was used for protein quantification. After protein quantification, the loading buffer was added to each sample and heated in a water bath at $100^{\circ} \mathrm{C}$ for 5 minutes to prepare the sample. The sample was separated by $10 \%$ Bis-Tris gel electrophoresis, transferred to PVDF membrane, blocked in 5\% skim milk powder (w/ v) for $1 \mathrm{~h}$, and then incubated with anti-Tyrosine Hydroxylase (Abcam, 1:1000), anti-MHC class II (Santa Cruz, 1:500), anti-Arginase-1 antibody (Cell Signaling Technology, $1: 1000)$ at $4^{\circ} \mathrm{C}$ overnight. The sample was incubated with goat anti-rabbit IgG or goat anti-mouse IgG (Beyotime, 1:1000) at room temperature for 1 h. Blots were imaged by the ECL chemiluminescence (Millipore, USA) and a Gel Image System (GE, USA). Densitometry was performed by using Image J software.

\section{Immunocytochemistry and \\ Immunofluorescence Staining}

Briefly, the mice were deeply anesthetized and sacrificed by cardiac perfusion with normal saline and $4 \%$ paraformaldehyde successively. The whole brain was taken out and fixed with paraformaldehyde. After dehydration, the brain was sliced into $20 \mu \mathrm{m}$ coronal sections by frozen sectioning and the sections containing SNpc were collected.

Brain sections were treated with $3 \% \mathrm{H}_{2} \mathrm{O}_{2}$ at room temperature to inactivate endogenous enzymes, immersed in $0.01 \mathrm{M}$ sodium citrate buffer for thermal repair, and blocked with goat serum. Then dropped the primary antiTH antibody (Abcam, 1:400) and incubated overnight at $4^{\circ} \mathrm{C}$. Then, the sections were incubated with goat antirabbit IgG secondary antibody (Beyotime, $1: 50$ ) at $37^{\circ} \mathrm{C}$ for $1 \mathrm{~h}$. DAB served as a chromogen and observed under a microscope (Nikon, Japan). Numbers of TH positive cells in SNpc were counted in a blind manner.

Immunohistofluorescence double staining of Iba-1/CD16 and Iba-1/CD206 were done as follows. The frozen tissue sections were treated with $0.03 \%$ Triton to make the tissues permeable, and donkey serum was added to block after permeabilization. After blocking, add primary antibody and incubate overnight at $4^{\circ} \mathrm{C}$. Primary antibodies: goat anti-Iba-1 (Abcam, 1:400), rabbit anti-CD16 (Affinity Biosciences; 1:200), rabbit anti-CD206 (Abclonal, 1:50). Then the corresponding secondary antibodies, coupled to CoraLite488conjugated goat anti-rabbit IgG (proteintech, 1:500) and Alexa Fluor-conjugated donkey anti-goat IgG (Abcam, 1:1000), were used. The sample was covered with an antifluorescence quenching mounting plate and examined with 
a fluorescence microscope (Nikon, Japan). The morphological changes of the microglia in the substantia nigra of the mouse brain were observed, and the number of branches and the number of branch endpoints per 20 microglia were calculated. $^{25}$

\section{Enzyme Linked Immunosorbent Assay (ELISA)}

The peripheral blood of the mice was collected and centrifuged at $3000 \mathrm{r} / \mathrm{min}$ for $15 \mathrm{~min}$, and the upper serum was used to examine the cytokine concentration. The concentration of IL-1 $\beta$ (R\&D, USA, MLB00C), IL-6 (R\&D, USA, M6000B), TNF- $\alpha$ (R\&D, USA, MTA00B) and IL10 (R\&D, USA, M1000B) in the serum were detected by the double antibody sandwich method, and the operation was performed according to the kit instructions.

\section{RT-PCR Analysis}

The mice were sacrificed, and the midbrain was quickly isolated on ice and stored in an RNA store solution at $-80^{\circ} \mathrm{C}$. The midbrain tissue was taken out from $-80^{\circ} \mathrm{C}$, thawed on ice, and tissue lysate was added to extract total RNA. Total RNA was isolated from the midbrain tissue and reverse transcribed into cDNA. The cDNA was reacted with corresponding primers and SYBR SuperMix. The above operations were carried out according to the kit instructions (Eastep ${ }^{\circledR}$ Super Total RNA Extraction Kit, GoScriptTMReverse Transcription Mix, Oligo (DT), SuperReal PreMix Plus (SYBR Green)). All the data were calculated using the $\mathrm{Ct}$ method $^{26}$ and normalized to the GAPDH, with the control group as the reference. The specific primer descriptions are shown in Table 1.

\section{Transcriptome Analysis}

The midbrain tissue was separated on ice and stored in RNA store solution (TIANGEN, Beijing, China). The first total RNA was extracted, using NEBNext ${ }^{\circledR}$ UltraTM RNA library preparation kit to generate a sequencing library, and adding the index code to the attribute sequence of each sample. The library preparations were sequenced on the Illumina HiSeq platform. Use Galaxy's genome analysis tool to process all sample data, and use the Salmon onestep quantitative method in the analysis tool to calculate the TPM (Transcripts Per Million) value of each set of data. We use the DESeq2 software package in the analysis tool to identify the differentially expressed genes between
Table I Primer Sequence

\begin{tabular}{|c|c|c|}
\hline $\begin{array}{l}\text { Gene } \\
\text { Name }\end{array}$ & & Gene Sequence \\
\hline \multirow[t]{2}{*}{ GAPDH } & Forward & AAGAAGGTGGTGAAGCAGGCATC \\
\hline & Reverse & CGGCATCGAAGGTGGAAGAGTG \\
\hline \multirow[t]{2}{*}{ MHC class II } & Forward & GGCTCCTCAAGCGACTGTGTTC \\
\hline & Reverse & CACCGTCTGCGACTGACTTGC \\
\hline \multirow[t]{2}{*}{ Arginase-I } & Forward & TGCTCACACTGACATCAACACTCC \\
\hline & Reverse & TCTACGTCTCGCAAGCCAATGTAC \\
\hline \multirow[t]{2}{*}{ IL-I $\beta$} & Forward & CCAGGATGAGGACATGAGCA \\
\hline & Reverse & CGGAGCCTGTAGTGCAGTTG \\
\hline \multirow[t]{2}{*}{ IL-6 } & Forward & AGACTTCCATCCAGTTGCCTTCTTG \\
\hline & Reverse & CATGTGTAAAGCCTCCGACTTGTG \\
\hline \multirow[t]{2}{*}{ TNF- $\alpha$} & Forward & GCGACGTGGAACTGGCAGAAG \\
\hline & Reverse & GCCACAAGCAGGAATGAGAAGAGG \\
\hline \multirow[t]{2}{*}{ IL-I0 } & Forward & CTGCTATGCTGCCTGCTCTTACTG \\
\hline & Reverse & ATGTGGCTCTGGCCGACTGG \\
\hline \multirow[t]{2}{*}{ Agrp } & Forward & CCAATGGCACAGCAGGTACTAAGG \\
\hline & Reverse & TAGGTCGGCACACTCCAGCAG \\
\hline \multirow[t]{2}{*}{ |s| | } & Forward & CACCTTGCGGACCTGCATTGC \\
\hline & Reverse & CTGCTGCTGGAGCTGCTTCATC \\
\hline \multirow[t]{2}{*}{ Pomc } & Forward & GCGCTTCCGCTGGAGCAACC \\
\hline & Reverse & GCGTTCTTGATGATGGCGTTCTTG \\
\hline \multirow[t]{2}{*}{ Nkx2-I } & Forward & ACCGCCGCCTACCACATGAC \\
\hline & Reverse & GCTGTTCCGCATGGTGTCCTG \\
\hline
\end{tabular}

different groups; we use DAVID to analyze the differentially expressed genes. $P$ value $<0.05$ is considered significant. Then, RT-PCR was performed to validate the differential gene.

\section{Protein-Protein Interaction Network Through STRING Database}

The string online database was used to analyze inflammation-related indicators (IL-6, TNF- $\alpha$, IL-1 $\beta$, CD16, IL-10, CD206, ARG-1) and the transcriptome and to verify opposite regulatory genes (Agrp, Isl1, Nkx2-1, Pomc). The protein-protein interaction (PPI) information was parsed from STRING (Search Tool for the Retrieval of Interacting Genes/ Proteins) database version 11.0 (https://string-db.org/) ${ }^{27}$. 


\section{Statistical Analyses}

SPSS 22.0 software was used for data analysis. Data are presented as mean \pm SEM.

Statistical analysis was performed using a one-way analysis of variance and the Bonferroni's multiple comparison test, and $P<0.05$ is considered statistically significant.

\section{Results}

\section{Identification of Chemical Constituents in DZF}

The chromatogram of DZF was obtained using the process described in "Method 2.2.". The main compounds were detected and identified, including Caffeic acid (1),
5-Hydroxymethyl furaldehyde (2), Aucubin (3), Geniposidic acid (4), Dendrobiumane B (5), 3-Caffeoylquinic acid (6), 10Gingerdione (7), (+)-Cycloolivil or (-)-Olivil (8',8),6-Shogaol (9), Cinnamic acid (10), 10-Gingerol (11), Dendromoniliside A (12), Genipin (13), Nobilonine (14), Dendramine (15), 6-Gingerol (16), Dendrobiumane A (17), 8-Gingerol (18), and Hexadecanoic acid (19). The chemical structures of these compounds are shown in Figure 2.

\section{DZF Improves Locomotor Dysfunction in Parkinsonian Mice}

Locomotor dysfunction often occurs in PD. In order to evaluate the potential protective effect of DZF on locomotor
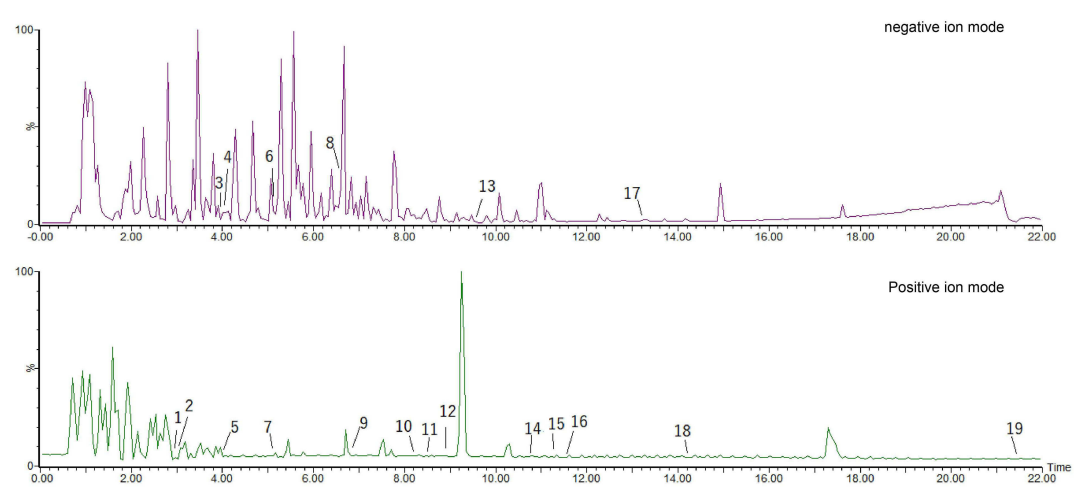

(5)
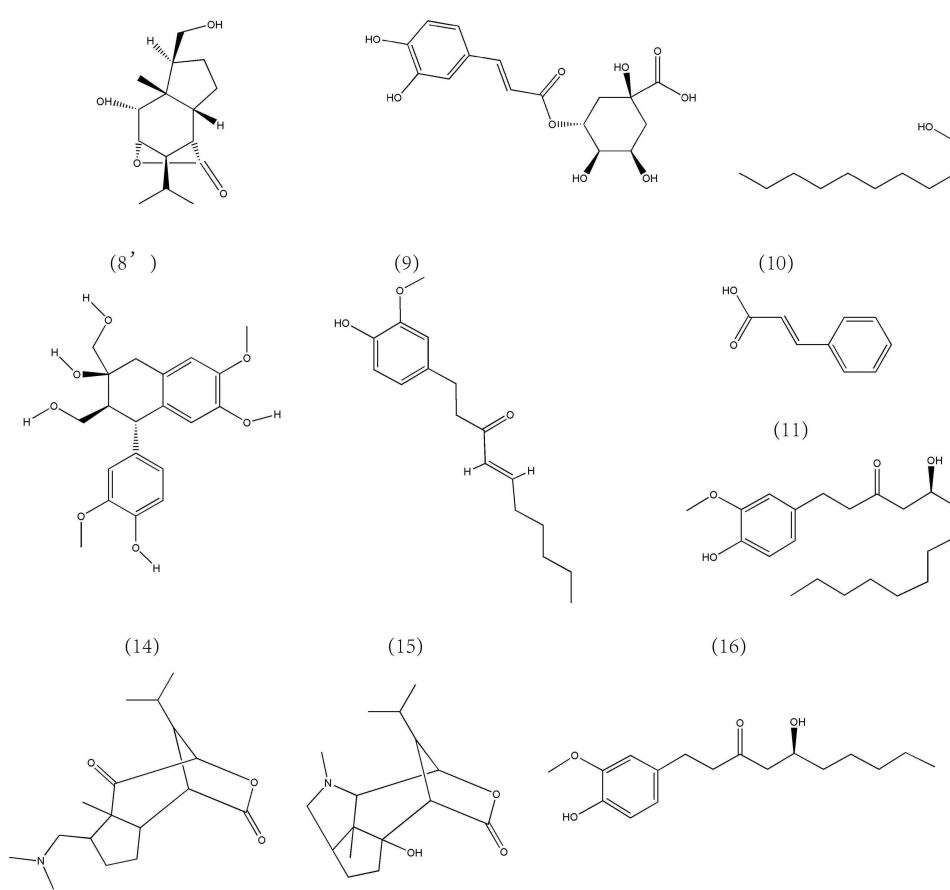

(6)
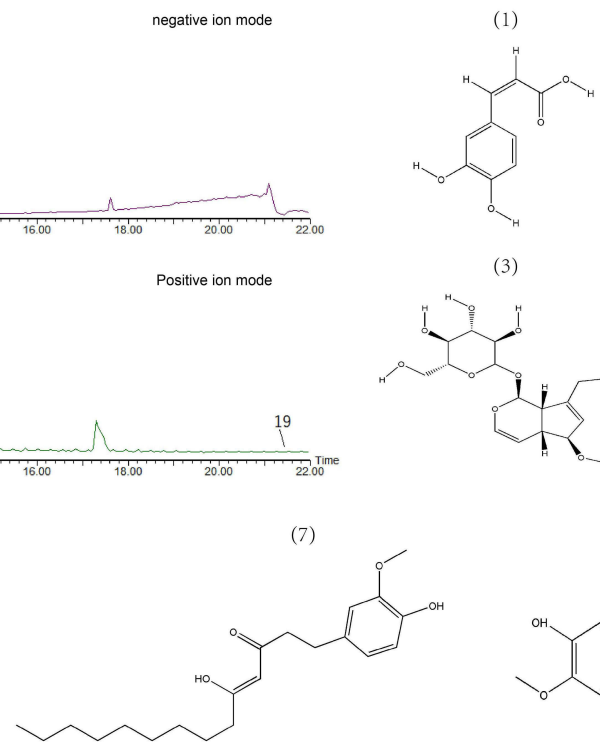

(2)
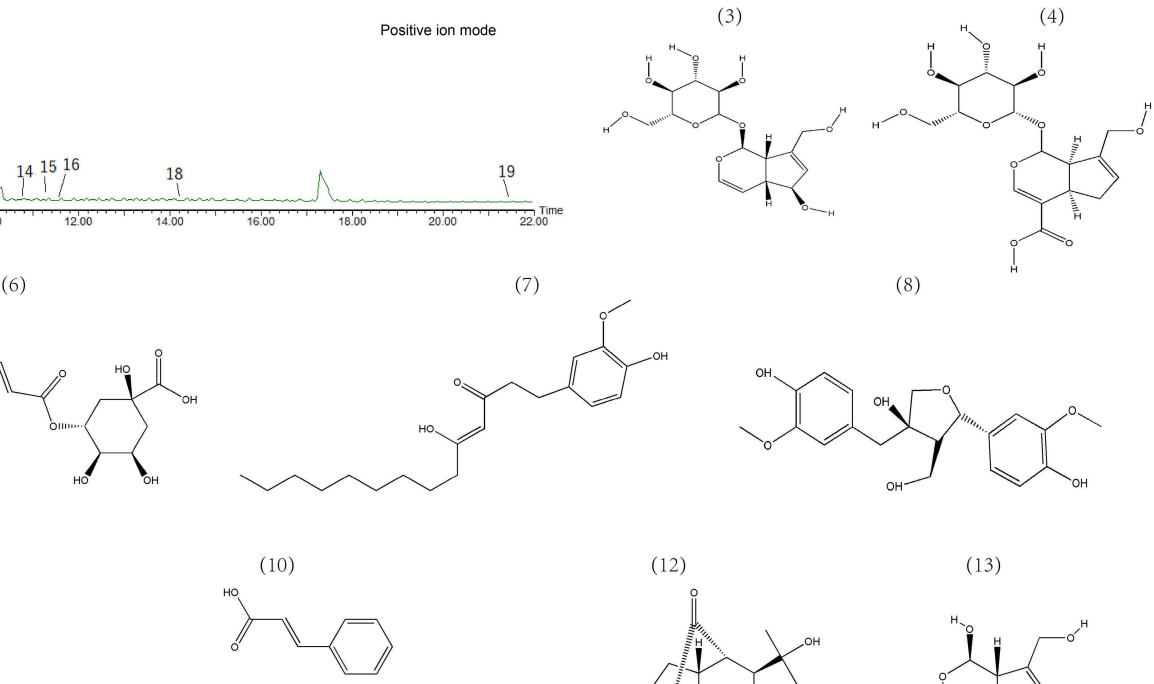

(11)
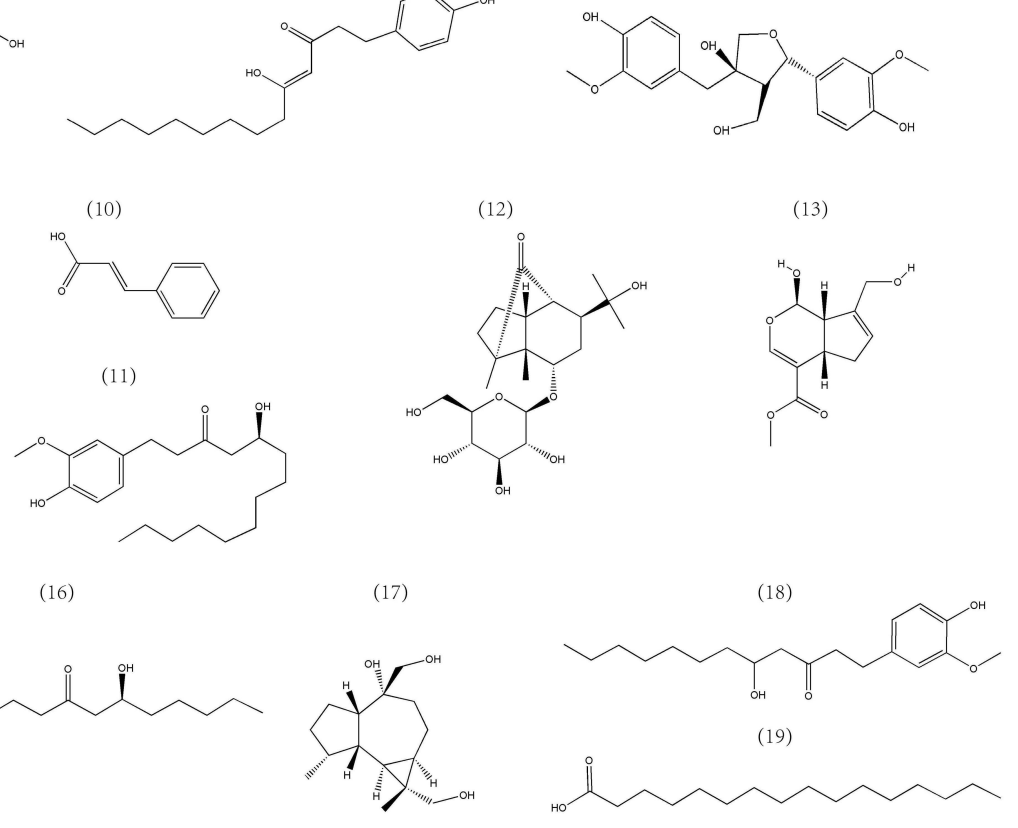

(17)

(13)
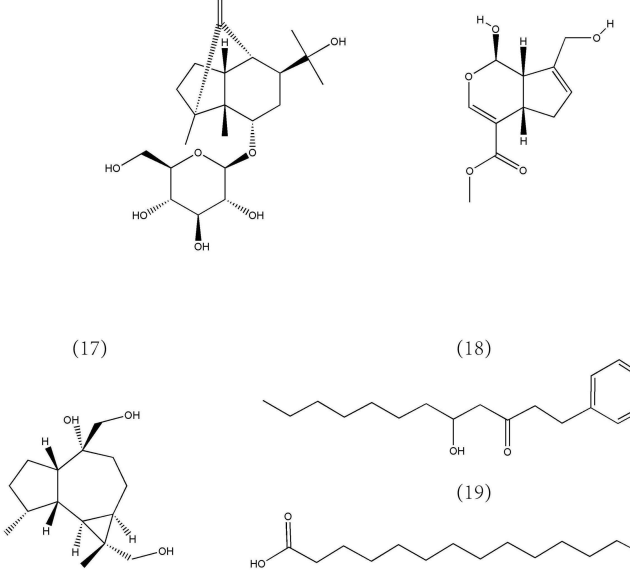

Figure 2 The chromatogram of Duzhong Fang extract and the structure of some components. (I), 5-Hydroxymethyl furaldehyde (2), Aucubin (3), Geniposidic acid (4), Dendrobiumane B (5), 3-Caffeoylquinic acid (6), I0-Gingerdione (7), (+)-Cycloolivil or (-)-Olivil (8',8),6-Shogaol (9), Cinnamic acid (I0), I0-Gingerol (1I), Dendromoniliside A (12), Genipin (13), Nobilonine (14), Dendramine (15), 6-Gingerol (16), Dendrobiumane A (17), 8-Gingerol (18), and Hexadecanoic acid (19). 
dysfunction in parkinsonian mice, we performed behavioral tests on mice to evaluate their muscle strength, mobility and balance. Through behavioral testing, compared with the Control group, MPTP-induced parkinsonian mice showed locomotor dysfunction, including longer climbing time, shorter falling time of the rotating rod, lower grip value, and lower traction score. However, compared with MPTP group, MPTP-DZF and MPTP-S significantly improved the MPTP-induced motor impairment, and were statistically significant. The results are shown in Figure 1E-H.

\section{DZF Rescued Striatal Dopamine Content of Parkinsonian Mice}

In order to evaluate the potential neuroprotective effects of DZF on brain function, the concentration of the striatal neurotransmitter DA and its metabolites (DOPAC and HVA) were detected by HPLC-ECD. As expected, the DA level of the striatum of the MPTP group mice was significantly reduced compared with the Control group mice, and the DA level of the striatum of the MPTP-DZF group mice was significantly increased compared with the MPTP group mice (Figure 1B). Similarly, DOPAC and HVA were also decreased in MPTP group mice compared with Control group mice. However, in MPTP-DZF group, DOPAC and HVA were increased not evident compared with the MPTP group mice (Figure 1C and D). Curiously, the HVA level of the Selegiline group was significantly higher than the Control group (more than 3 times), which has also been observed previously. ${ }^{18}$ We reasoned that this may be related to the different degradation pathways of HVA inside and outside nerve cells.

\section{DZF Improves Dopaminergic Neurons and TH Levels in Parkinsonian Mice}

In order to examine the effect of DZF on the survival of dopaminergic neurons in SNpc and verify whether $\mathrm{TH}$ expression corresponds to DA level, we characterized $\mathrm{TH}$ expression by immunohistochemical staining and Western blot analysis in SNpc. Immunohistochemical staining revealed a significant loss of $\mathrm{TH}^{+}$dopaminergic neurons in parkinsonian mice compared to controls that were partially rescued by DZF and Selegiline (Figure 1I and J). Similarly, Western blot analysis of midbrain tissue showed that $\mathrm{TH}$ expression in parkinsonian mice was lower compared to Control, DZF and Selegiline inhibited the reduction of TH expression in parkinsonian mice (Figure $1 \mathrm{~K}$ and $\mathrm{L}$ ).

\section{DZF Alleviates MPTP-Mediated Peripheral and Central Inflammation}

To further explore the anti-inflammatory benefit of DZF, we characterized serum and midbrain level of proinflammatory factor (IL-1 $\beta$, IL-6, and TNF- $\alpha$ ) and antiinflammatory factor (IL-10 and IL-1r $\alpha$ ) by ELISA (Figure 3A-D) and RT-PCR (Figure 3E-H), respectively. As shown in Figure 3, compared with the Control group, the levels of IL-1 $\beta$, IL- 6 and TNF- $\alpha$ in the serum and midbrain of the MPTP group mice were increased; compared with the MPTP group, the levels of inflammatory factors IL-1 $\beta$, IL- 6 , and TNF- $\alpha$ in the serum and midbrain tissue of the MPTP-DZF and MPTP-S groups decreased, and the levels of IL-1r $\alpha$ and IL10 were significantly increased. The reduction of serum IL-1 $\beta$ in the MPTP-DZF group was more significant than that in the MPTP-S group. However, the levels of IL-10 and IL-1 r $\alpha$ in the MPTP-S group increased more significantly than those in the MPTP-DZF group.

\section{DZF Blocks the MPTP-Induced Microglia Reactivity State}

The reactivity of brain microglia focused on the SNpc is highly relevant for PD. ${ }^{28}$ After the microglia is activated, its morphology also changes, such as branching more from the resting state to round amoeba cells with fewer branches. Therefore, we observed the morphological changes of microglia in the mouse brain $\mathrm{SNpc}$, and the number of branches and branch endpoints of every 20 microglia cells were counted. In order to study whether DZF modifies microglia activity within the midbrain in parkinsonian mice, we compared by Western blot and immunofluorescence staining the expression profiles of Iba-1, microglial marker, on the microglia. Western blot analysis showed that MPTP led to a significant increase in Iba-1 protein level in SNpc. However, upon treatment with DZF and Selegiline significantly decreased Iba-1 protein (Figure 4A and B).

As can be seen from Iba-1 immunofluorescence staining, the resting microglia was ramified with multiple branches, whereas the microglia in the MPTP group was activated, had hypertrophied soma and shortened branches. Compared with MPTP-treated mice, microglia in DZF and Selegiline-treated mice displayed an increased number of branches and of branch endpoints (Figure 4C-E). 

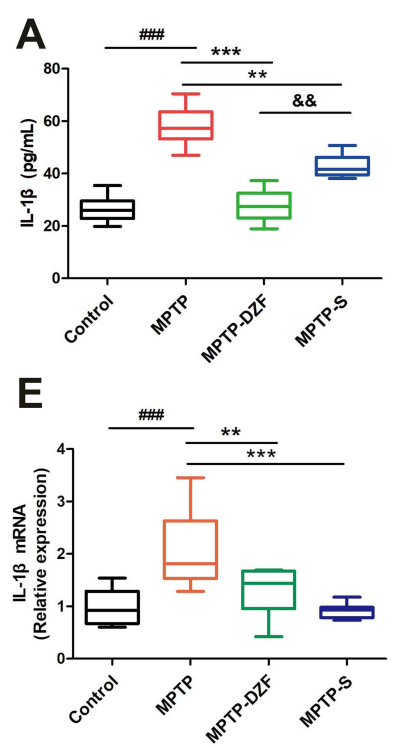

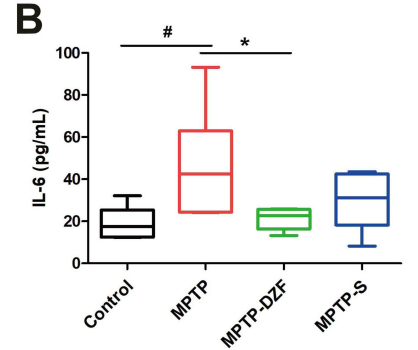

$\mathbf{F}$

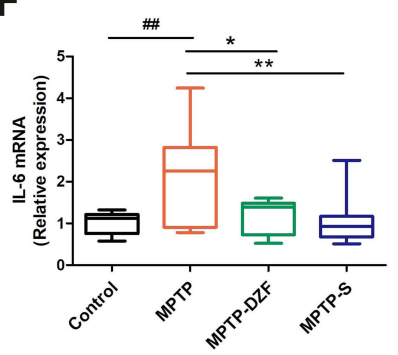

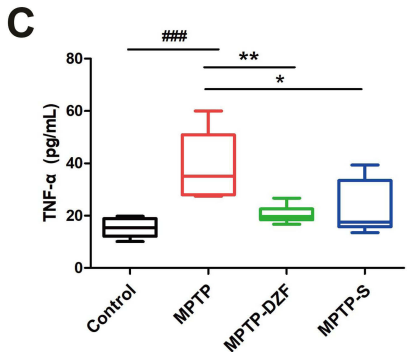

G

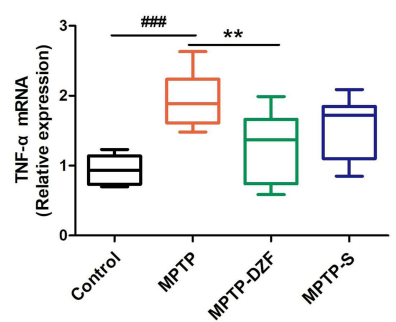

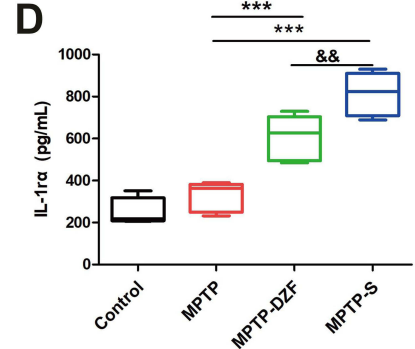

H

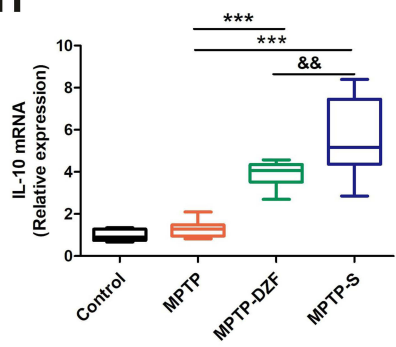

Figure 3 DZF alleviates peripheral and neuroinflammation in MPTP-induced parkinsonian mice. (A-D) ELISA analysis of cytokines (IL-I $\beta$, IL-6, TNF- $\alpha$, and IL-I0) in the peripheral blood of parkinsonian mice. (E-H) RT-PCR for midbrain mRNA expressions of inflammatory cytokines. Data represent the means \pm SEM; Statistics one-way

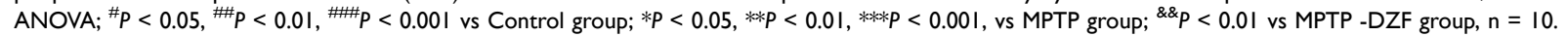

\section{DZF Modulated the Microglial Phenotypic Profiles in Parkinsonian Mice}

To further observe the effect of DZF on the change of microglia phenotype in the midbrain, phenotypic markers of microglia were tested. First, mRNA and protein expression of classically activated microglia marker (MHC-II) and alternatively activated microglia marker (Arg-1) were analyzed by RT-PCR and Western blot. The results showed that pro-inflammatory (MHC-II) gene and protein increased in the MPTP group, while the anti-inflammatory (Arg-1) gene and protein expression was less than the Control group. DZF and selegiline markedly restrained the up-regulation of the pro-inflammatory marker and DZF elevated the downregulation of the anti-inflammatory marker induced by MPTP treatment (Figure 5A-E).

Then, the phenotype of microglia was examined by the co-expression of the classical marker CD16 (red) and alternative marker CD206 (red) with microglia marker Iba-1 (green). As shown in Figure 6A-D, DZF and selegiline significantly increased the number of CD206 $/ \mathrm{Iba}-1^{+}$ cells in the midbrain of MPTP-exposed mice. However, the number of $\mathrm{CD} 16^{+} / \mathrm{Iba}-1^{+}$cells had a tend to reduce which was not statistically significant.

\section{Transcriptomics Analysis of the Effect of DZF on Gene Expression}

To investigate the underlying common molecular mechanisms that regulate microglial dysfunction, we analyzed transcriptomes during disease progression in parkinsonian mice. The obtained genes were screened and compared for differential genes. A total of 49 differential genes (Figure 7Aa, Table 2A) were compared between the MPTP group and the Control group, of which 38 were upregulated and 11 were down-regulated. Comparing the DZF group with the Model group, a total of 17 differential genes were obtained, all of which were down-regulated (Figure 7Ab, Table 2B). Among them, reverse-regulated 7 genes, including: AGRP, ISL1, AC154734.1, NKX2-1, POMC, SYTL4, GAL, were further verified by RT-PCR. Ultimately confirming that there were four genes, AGRP, POMC, ISL1, NKX2-1, have the same trend between transcriptome (Figure 7B) and RT-PCR analysis (Figure 7C-G).

Using the String database, we further performed protein interactions between the validated genes and effect indicators, and it was found that POMC gene is directly related to inflammatory factors and microglial phenotypic markers, as shown in Figure 7H. That is to say, it is speculated that POMC gene may be a direct target of DZF to regulate microglial phenotype and neuroinflammation.

\section{Discussion}

In vivo evidence provided by this study showed that DZF, a traditional Chinese prescription, restored impaired movement and dopamine loss in MPTP-induced parkinsonian mice. Indeed, we provide a mechanistic explanation by showing that DZF exerts its beneficial neuroprotective effects by limiting systemic inflammation and microglia reactivity. A 


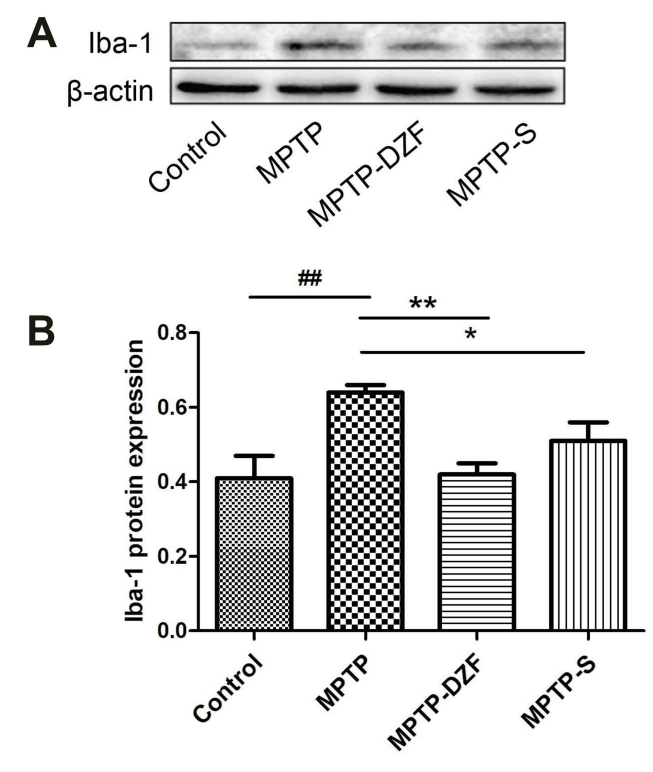

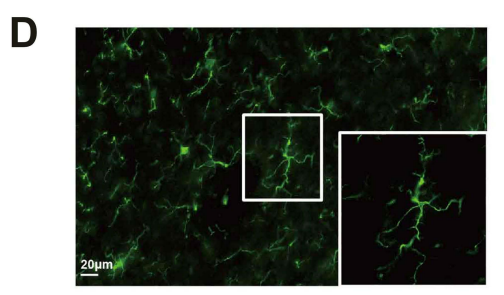

Control

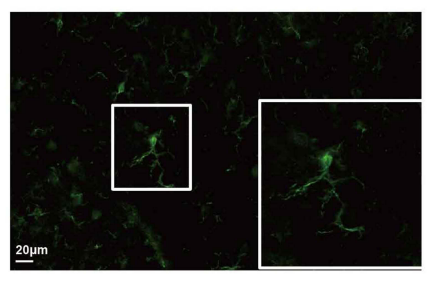

MPTP-DZF

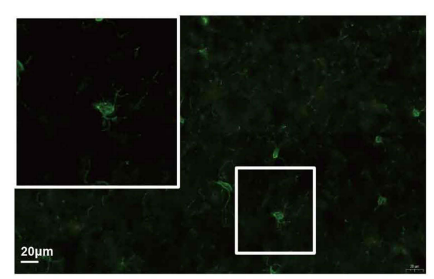

MPTP

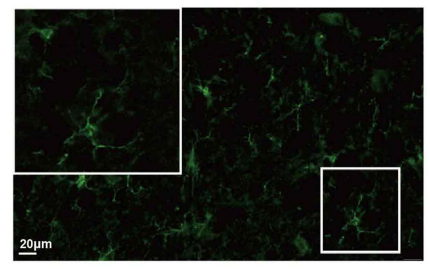

MPTP-S

E
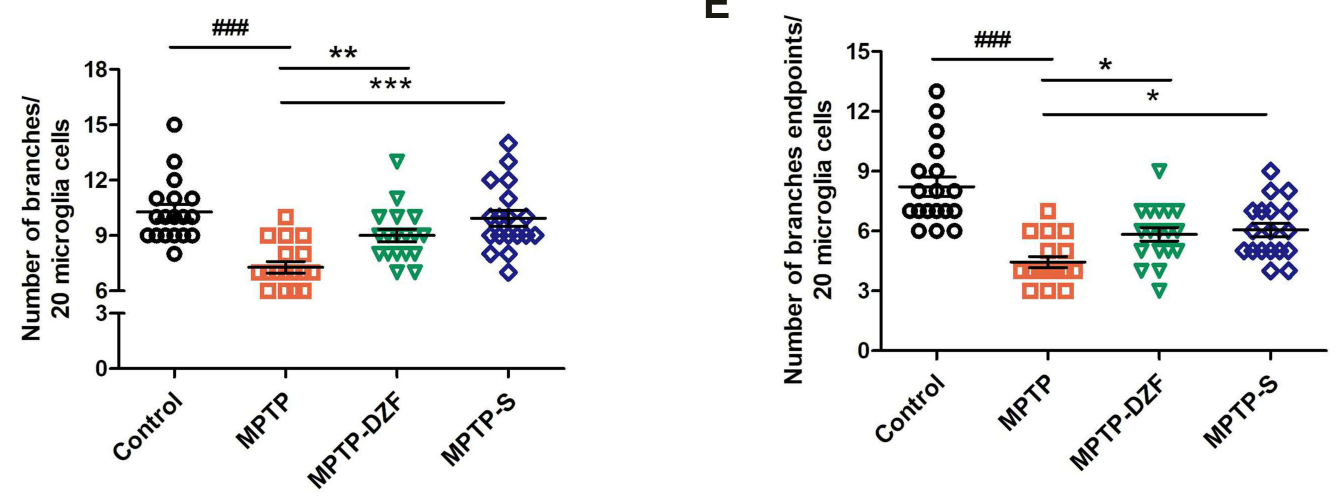

Figure 4 DZF alleviates microglial reactivity in the SNpc of parkinsonian mice. (A) Representative Western blot of midbrain Iba-I expression. (B) The intensity of bands was quantified for lba-I following normalization to $\beta$-actin. (C) Photomicrographs of immunofluorescence staining for microglial cells. (D) Average number of branches, (E) branches endpoints of microglia in the SNpc. Six visual fields were randomly selected and 20 cells in each visual field were counted. Data represent the means \pm SEM;

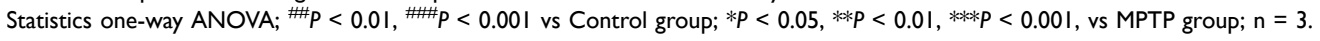

model summarising our results is show in Figure 8. Consistent with a previous study showing that MPTP-induced PD promotes enhanced motor impairment in mice, ${ }^{29}$ our results show that parkinsonian mice display motor dysfunctions and a decrease in striatal neurotransmitters. In contrast, parkinsonian mice that received DZF showed significant recovery of motor function and $\mathrm{DA}$ in the striatum. DA as a neurotransmitter plays an important role in regulating balance and movement, ${ }^{30}$ our results indicate that DZF can affect the DA concentration in the striatum and inhibit the loss of dopaminergic neurons in the SNpc. An inflammatory environment can enhance $\alpha$-synuclein aggregation and propagation, and progression of PD. ${ }^{31,32}$ Intriguingly, in our study, DZF not only improved motor impairment but also reduced peripheral and central inflammation in parkinsonian mice. In addition, there was a significant induction of the anti-inflammatory cytokine IL-10.

Microglia, a major type of immune cell in the central nervous system (CNS), performs key macrophagefunctions, such as clearance of dying cells and debris, and immune surveillance and response, et al. ${ }^{33}$ Increasing evidence implicates microglial reactivity is an early and characteristic feature of PD. ${ }^{34}$ The clinical and animal studies have shown that through the secretion of inflammatory mediators, microglia participates in the development and processing of PD pathology. ${ }^{35-37}$ In brain regions, SNpc has a high density of microglia ${ }^{38}$ and the selective vulnerability of dopaminergic neurons to inflammatory attack by reactive microglia. ${ }^{39}$ In the $\mathrm{SNpc}$ of chronic Parkinsonian macaques, microglial cell processes 
A

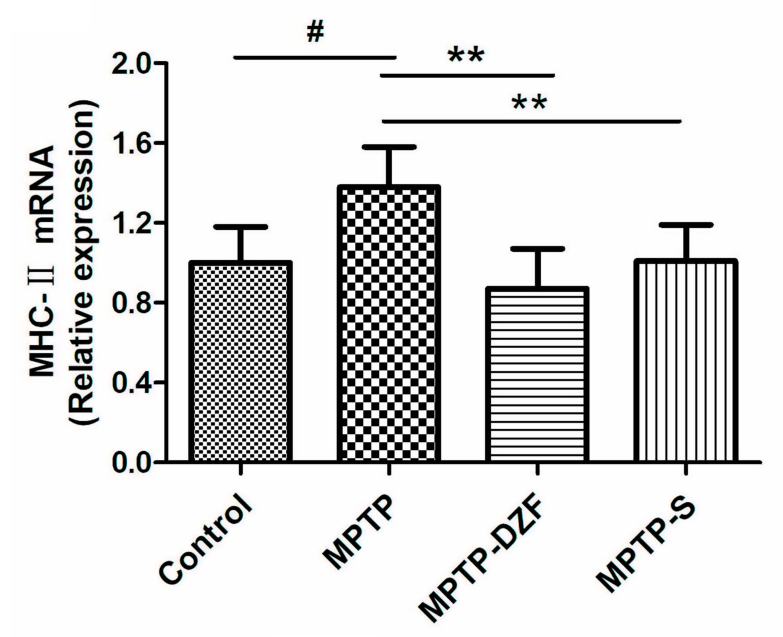

B

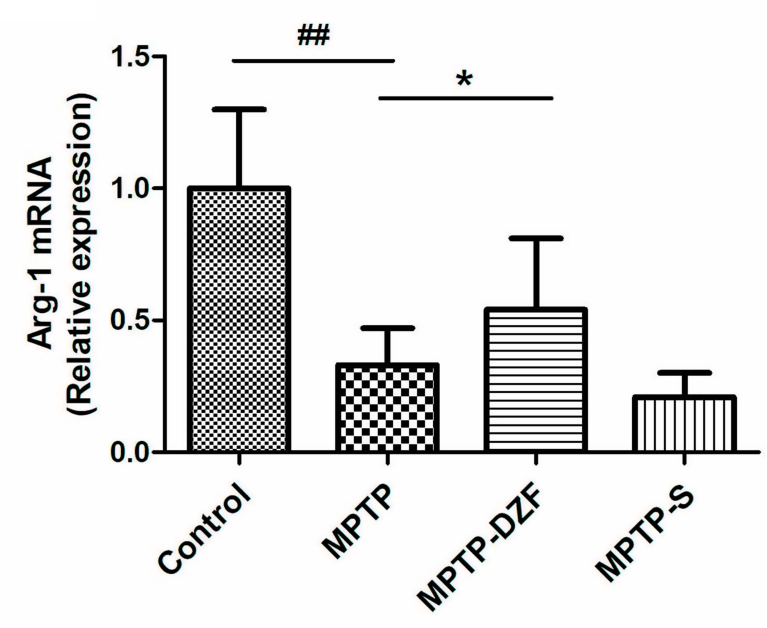

C $\mathrm{MHC}-\Pi \sim$

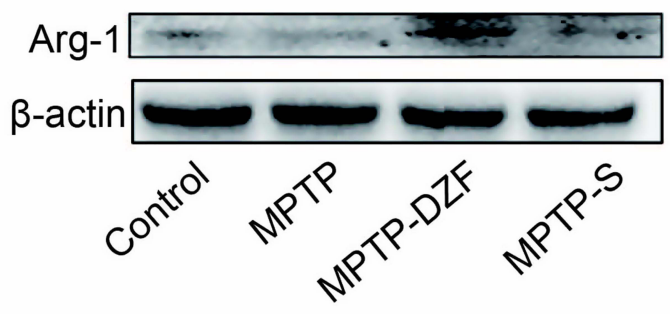

D

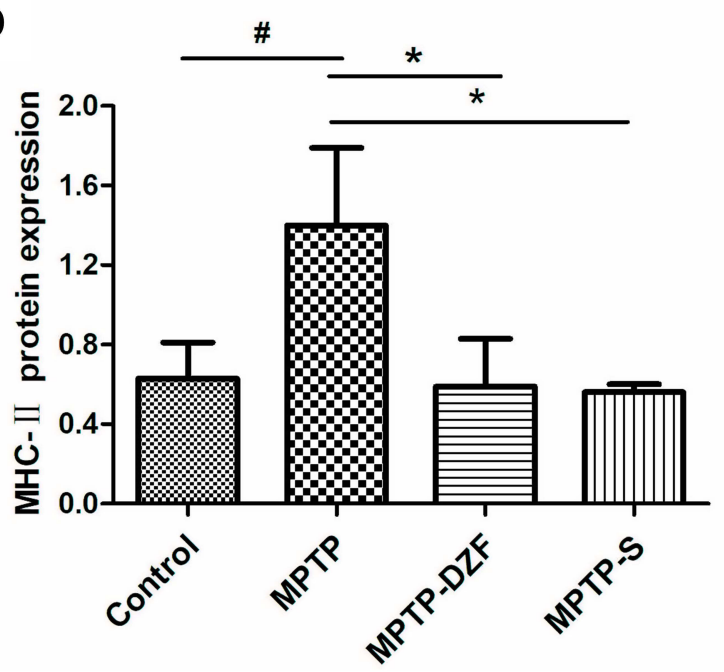

$\mathrm{E}$

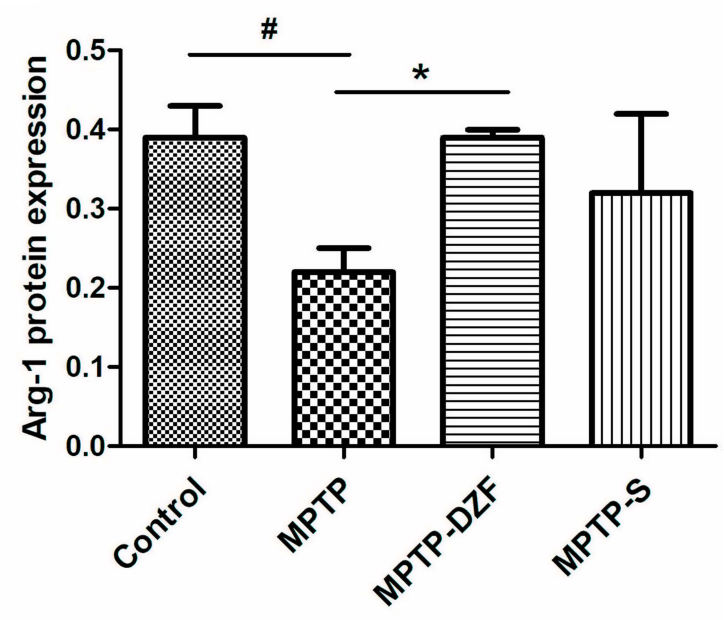

Figure 5 Western blot was used to detect the effect of DZF on the inflammatory response of microglia. (A and B) RT-PCR analysis of MHC-II and Arg-I mRNA expression in parkinsonian mice. (C) Representative Western blot of midbrain MHC-II and Arg-I protein expression. (D and E) The intensity of bands was quantified for MHC-II and Arg-I following normalization to $\beta$-actin. Data represent the means \pm SEM; Statistics one-way ANOVA; ${ }^{\#} P<0.05,{ }^{\#} P<0.0$ I, vs Control group; ${ }^{*} P<0.05$, ** $P<0.0$ I, vs MPTP group; $\mathrm{n}=10$ for RT-PCR. $\mathrm{n}=3$.

and cell bodies establish contacts with dopaminergic neurites and cell bodies. ${ }^{40}$ These findings emphasize the regulation of microglia reactivity in maintaining brain integrity. Yet, increased reactivity of microglia has been shown to promote microglia-mediated neuronal damage. ${ }^{41,42}$ Here, we found that the number of microglia marker Iba-1 was significantly increased in the midbrain of parkinsonian mice. Consistently, the body area of microglia represents the morphological changes of activated microglia. Unlike resting microglia, activated microglia 

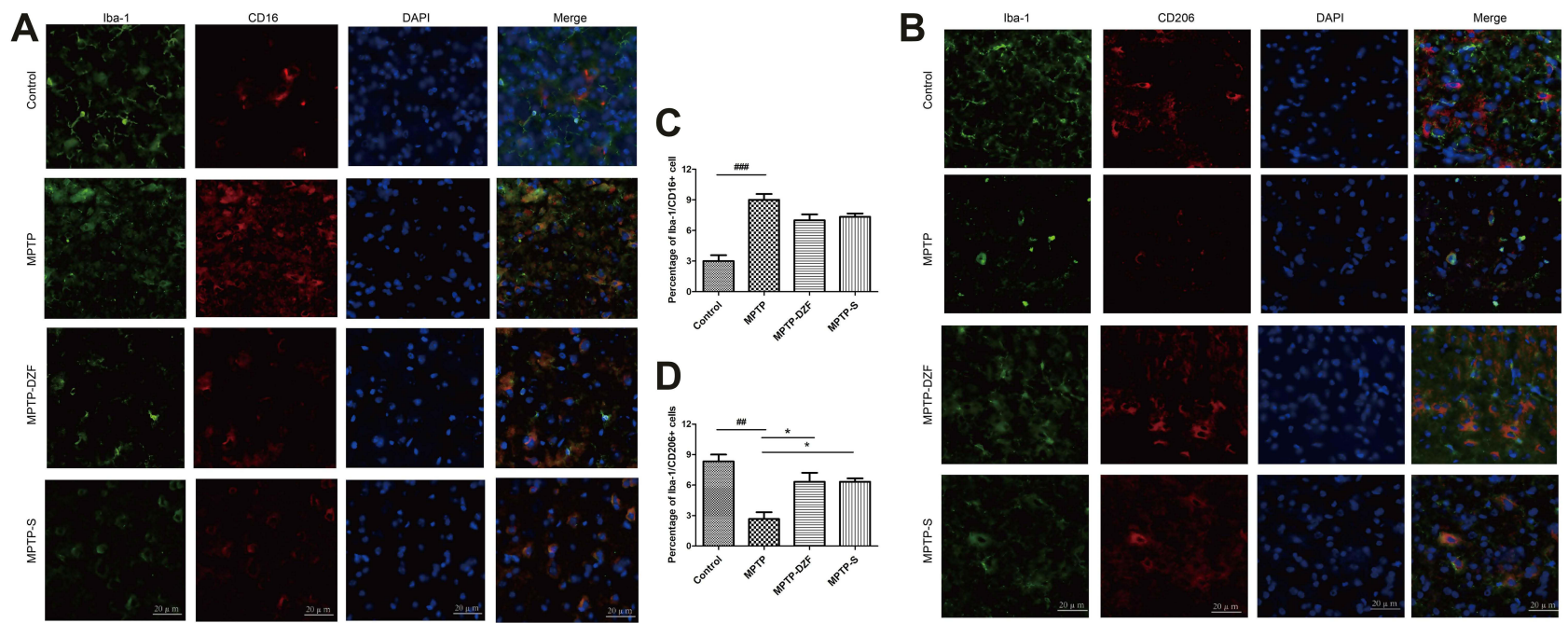

Figure 6 Immunofluorescence double staining of inflammatory marker CDI6 and anti-inflammatory marker CD206 on microglia in the substantia nigra of mice. (A) Staining of Iba-I (green) and CDI6 (classical microglia marker, red) in the SNpc and (B) quantification of the percentage of CDI6 ${ }^{+} / \mathrm{lba}-\mathrm{I}^{+}$cell. $(\mathbf{C})$ Double staining of Iba-I (microglia marker, green) and CD206 (alternative microglia marker, red) in the SNpc for immunofluorescence pictures and (D) quantification of the percentage of CD206 ${ }^{+} / \mathrm{lba}^{-} \mathrm{I}^{+}$cell. Scale bar is $20 \mu \mathrm{m}$. Data represent the means \pm SEM; Statistics one-way ANOVA; ${ }^{\#} P<0.01,{ }^{\prime \prime} P<0.001$ vs Control group; ${ }^{*} P<0.05$, vs MPTP group; $\mathrm{n}=3$.
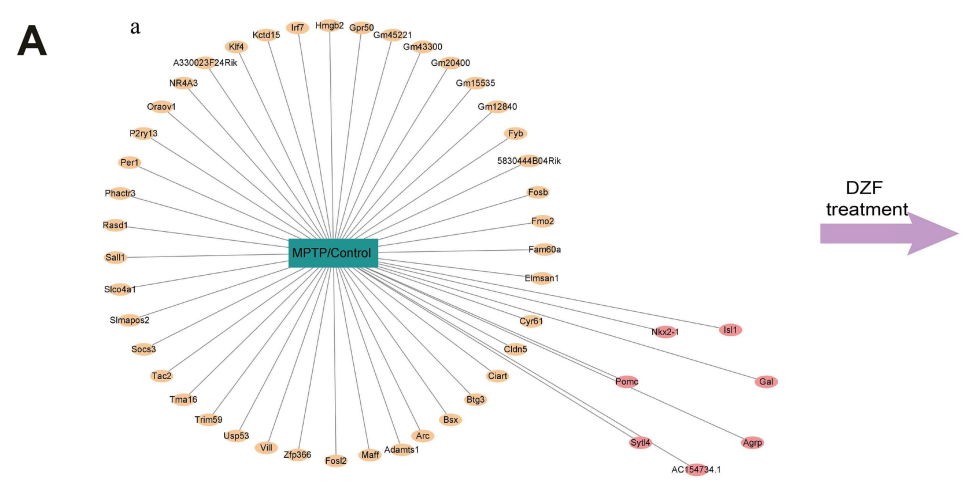

b

\section{B}

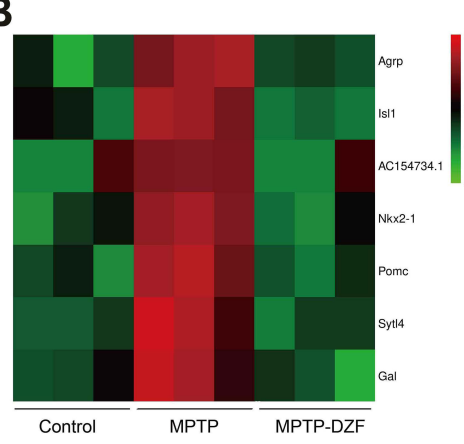

C

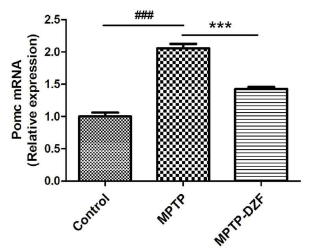

F

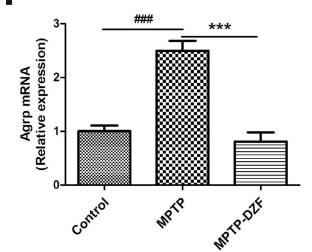

D

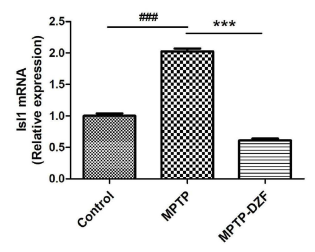

G

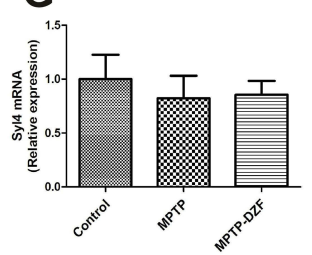

E

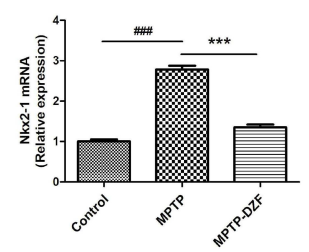

H

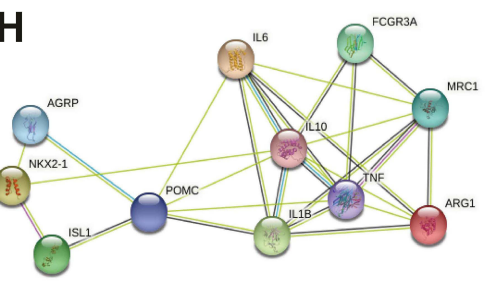

Figure 7 POMC gene is key target associated with the DZF to treat PD. (A) The oppositely regulated genes in the MPTP group compared with Control group and the MPTP group compared with the MPTP-DZF group. ((A)a represent differential genes between MPTP and Control groups. (A)b represent differential genes between MPTPDZF and MPTP groups. The pink in (A)a and the green in $(\mathbf{A}) \mathrm{b}$ are the same gene, but the expression trend is opposite). (B) Heatmap show reverse differential genes changed among the Control, Mode, and DZF groups. (C-G) RT-PCR verification of differential genes. (H) Interaction analysis of differentially genes and target effect. Protein-protein interaction was predicted between differentially genes and inflammation-related indicators using STRING database. Colored nodes represent query proteins and first shell of interactors; Edges represent protein-protein associations; The blue and purple lines represent known interactions; The green, red and blue lines represent predicted interactions. Data represent the means \pm SEM; Statistics one-way ANOVA; ${ }^{\#} p<0.00$ I vs Control group; $* * * P<0.001$, vs MPTP group; $n=3$. 
Table 2 Differentially Expressed Genes Between the Control, MPTP, and MPTP-DZF Groups Obtained from the Analysis of the Mice Midbrain Transcriptomics Results

\begin{tabular}{|c|c|c|}
\hline Gene & $\log 2(F C)$ & P-value \\
\hline \multicolumn{3}{|c|}{$\begin{array}{l}\text { (A) Differentially Expressed Genes Between the MPTP Group and the Control } \\
\text { Group }\end{array}$} \\
\hline Nkx2-I & 1.43 & $1.94 \mathrm{E}-19$ \\
\hline NR4A3 & 1.39 & $6.82 \mathrm{E}-24$ \\
\hline ACI54734.I & 1.31 & $1.52 \mathrm{E}-17$ \\
\hline Agrp & 1.24 & $9.57 \mathrm{E}-15$ \\
\hline Tmal6 & 1.14 & $1.27 \mathrm{E}-22$ \\
\hline Hmgb2 & 1.13 & $1.37 \mathrm{E}-14$ \\
\hline Syt14 & 1.11 & $6.86 \mathrm{E}-12$ \\
\hline Gm $/ 2840$ & 1.08 & $3.23 \mathrm{E}-1 \mathrm{I}$ \\
\hline Fmo2 & 1.03 & 4.57E-II \\
\hline Gpr50 & 1.00 & $4.64 \mathrm{E}-10$ \\
\hline Cyr6I & 0.99 & $8.7 \mathrm{IE}-\mathrm{II}$ \\
\hline Gm4522I & 0.96 & $3.86 \mathrm{E}-09$ \\
\hline Phactr3 & 0.94 & $1.46 \mathrm{E}-17$ \\
\hline Pomc & 0.94 & $2.33 \mathrm{E}-09$ \\
\hline Socs3 & 0.90 & $1.67 \mathrm{E}-08$ \\
\hline Gm20400 & 0.90 & $2.46 \mathrm{E}-08$ \\
\hline |s|| & 0.90 & $2.96 \mathrm{E}-08$ \\
\hline Slmapos2 & 0.88 & $3.6 \mathrm{IE}-08$ \\
\hline Tac2 & 0.86 & $3.24 \mathrm{E}-08$ \\
\hline Bsx & 0.86 & $1.31 \mathrm{E}-09$ \\
\hline Maff & 0.85 & $5.58 \mathrm{E}-08$ \\
\hline Rasd I & 0.83 & $9.23 \mathrm{E}-08$ \\
\hline Elmsan I & 0.83 & $1.27 \mathrm{E}-14$ \\
\hline Perl & 0.82 & $1.21 \mathrm{E}-15$ \\
\hline Fosl2 & 0.82 & $2.55 \mathrm{E}-08$ \\
\hline Slco4al & 0.81 & $1.92 \mathrm{E}-07$ \\
\hline Irf7 & 0.80 & $4.65 \mathrm{E}-07$ \\
\hline 5830444B04Rik & 0.80 & $5.62 \mathrm{E}-07$ \\
\hline Btg3 & 0.79 & $8.37 \mathrm{E}-08$ \\
\hline KIf4 & 0.79 & $1.61 \mathrm{E}-10$ \\
\hline Fosb & 0.78 & I.1IE-06 \\
\hline Vill & 0.77 & $2.08 \mathrm{E}-06$ \\
\hline Ciart & 0.74 & $7.62 \mathrm{E}-08$ \\
\hline Usp53 & 0.73 & $8.88 \mathrm{E}-13$ \\
\hline Adamts I & 0.72 & 7.87E-08 \\
\hline Fyb & 0.72 & $1.02 \mathrm{E}-05$ \\
\hline Gal & 0.71 & I.19E-05 \\
\hline Gm43300 & 0.71 & $1.28 \mathrm{E}-05$ \\
\hline Kctd I5 & -0.71 & $2.6 \mathrm{IE}-07$ \\
\hline Fam60a & -0.72 & $9.48 \mathrm{E}-06$ \\
\hline P2ryl3 & -0.72 & $5.47 \mathrm{E}-06$ \\
\hline Arc & -0.72 & $4.75 \mathrm{E}-07$ \\
\hline A330023F24Rik & -0.73 & $2.44 \mathrm{E}-09$ \\
\hline Gml5535 & -0.73 & $5.09 \mathrm{E}-06$ \\
\hline Oraovl & -0.74 & $1.75 \mathrm{E}-08$ \\
\hline Trim59 & -0.74 & 2. $10 \mathrm{E}-08$ \\
\hline Cldn5 & -0.78 & $6.54 \mathrm{E}-10$ \\
\hline SallI & -0.84 & $7.83 \mathrm{E}-13$ \\
\hline Zfp366 & -0.85 & $1.47 \mathrm{E}-07$ \\
\hline
\end{tabular}

(Continued)
Table 2 (Continued).

\begin{tabular}{|l|l|l|}
\hline Gene & Log2 (FC) & P-value \\
\hline \multicolumn{2}{|l|}{ (B) Differentially Expressed Genes Between MPTP-DZF Group and MPTP } \\
Group \\
\hline Col6al & -0.71233 & $5.78 \mathrm{E}-09$ \\
Slc47al & -0.73005 & $4.36 \mathrm{E}-08$ \\
Gal & -0.73546 & $4.29 \mathrm{E}-08$ \\
Faml79a & -0.7487 & $3.32 \mathrm{E}-08$ \\
Adamts13 & -0.76488 & $1.62 \mathrm{E}-08$ \\
CrabpI & -0.87835 & $1.79 \mathrm{E}-11$ \\
Syt14 & -0.89234 & $1.43 \mathrm{E}-11$ \\
Pomc & -0.91733 & $8.34 \mathrm{E}-12$ \\
Anpep & -0.92788 & $6.29 \mathrm{E}-12$ \\
Hdc & -0.98231 & $3.65 \mathrm{E}-13$ \\
Lbp & -1.0015 & $6.07 \mathrm{E}-15$ \\
Col23al & -1.07021 & $7.71 \mathrm{E}-20$ \\
Nkx2-I & -1.11077 & $1.09 \mathrm{E}-18$ \\
ACl54734.I & -1.18157 & $2.37 \mathrm{E}-21$ \\
IslI & -1.2237 & $1.10 \mathrm{E}-19$ \\
Agrp & -1.24157 & $2.1 \mathrm{E}-20$ \\
Npy & -1.3124 & $1.39 \mathrm{E}-24$ \\
\hline
\end{tabular}

are round, swollen, and small processes that transfer from branches to amoeba-like assets. ${ }^{43}$ As can be seen from Figure 4, DZF not only reduces the expression of Iba-1 but also with thin highly branched, suggesting a reduction in microglial reactivity after treatment.

Under physiological condition, microglia monitor the local environment to maintain the homeostasis of the CNS ${ }^{44}$ When it senses injury signals, it gets activated and releases inflammatory cytokines. ${ }^{45}$ Activated microglia are very plastic and may have multiple phenotypes. ${ }^{46}$ Recent studies have shown that microglia adopts two different functional phenotypes, consisting of phenotypes of "classical" reactivity and "alternative" reactivity. ${ }^{47,48}$ Although the dichotomy classical/alternative is now recognized as oversimplification, this classification is still useful for understanding the function of microglia in various brain diseases. ${ }^{49}$ When activated as a classical reactivity, microglia produces large amounts of neurotoxic mediators (IL-1 $\beta$, TNF- $\alpha$, NO) and worsen long-term neurological deficits after damage. ${ }^{50}$ During PD pathogenesis, classical reactivity microglia do not play a protective role, are harmful to the survival of dopaminergic neurons, and contribute to the aggregation of $\alpha$ synuclein. ${ }^{51}$ Conversely, damaged dopaminergic (DA) neurons also activate microglia to assume classical phenotype, setup a vicious cycle between dying neurons and acute inflammation. ${ }^{52-54}$ Aggregated $\alpha$-synuclein released into 


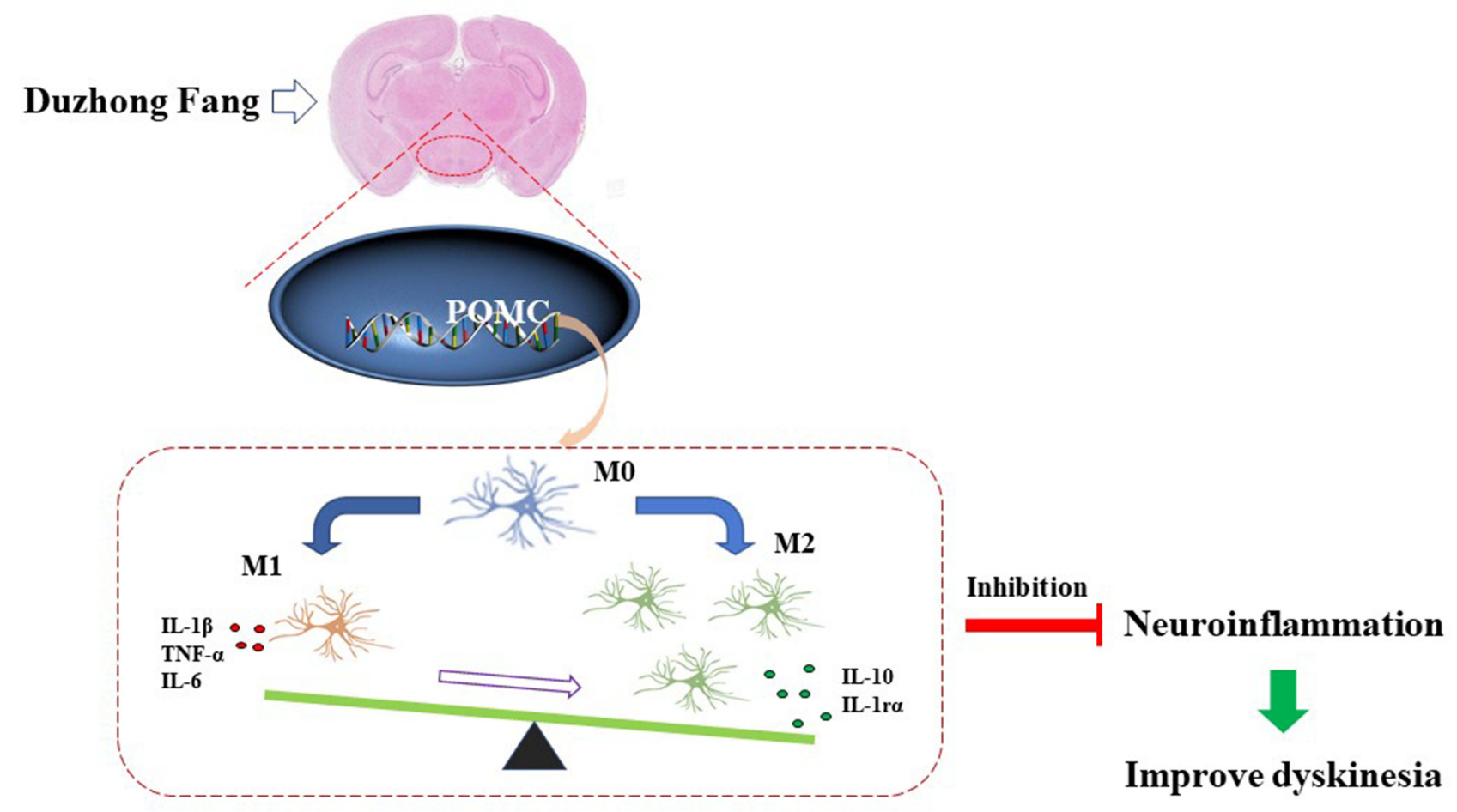

Figure 8 Schematic model of DZF attenuated POMC gene-driven MPTP-induced neuroinflammation in parkinsonian mice.

the extracellular space from neurons can directly switch microglia to a more classical phenotype. ${ }^{55}$

Contrary to the classical phenotype, alternative microglia have anti-inflammatory effects and promote wound healing and tissue repair. ${ }^{56,57}$ Alternative microglia secretes anti-inflammatory cytokines, such as IL-4, IL-13 and IL-10, initiating the alleviation of pro-inflammatory responses. ${ }^{58,59}$ It is generally thought that classical microglia usually becomes predominant in the early phase, ${ }^{60}$ and alternative microglia executes immunoresolution at a later phase. Whereas Michels et al suggest that early reactivity of classical microglia is followed by an overlap of both classical and alternative phenotypes. ${ }^{46}$ Similarly, mixed reactions similar to classical-like and alternative-like have been reported in animal models of epilepsy. ${ }^{61}$ However, currently, the reactivity of alternative phenotype in the pathogenesis of PD is still not clear. Since targeting classical/alternative microglia is expected to prevent the development of $\mathrm{PD}$, mastering the specific phase transition of classical/alternative phenotype within an appropriate time frame may provide better therapeutic effects. In our PD model, the expression of MHC-II and CD16 (classical microglia marker) was found to significantly increase in MPTP-induced mice, whereas DZF treatment significantly suppressed them expression. Conversely, DZF caused upregulation of the expression of alternative biomarkers Arg1 and CD206. That is, DZF can regulate the switch from classical to alternative microglia and alleviate inflammation.

Assessment of gene expression profiles in a genomics analysis further indicated the involvement of the molecular mechanism of DZF on microglia phenotype and against PD. In our study, there were 48 differential genes between the Model and Control groups, 17 genes between the DZF and Model groups. Eventually, seven oppositely regulated genes were found. Among them, only four reverse differential genes were ultimately validated by RT-PCR (ie, AGRP, POMC, ISL1, NKX2-1). Using the String database, we found that POMC gene is directly related to inflammatory factors and microglial phenotypic markers. Therefore, we considered that the microglia phenotype is involved in MPTP-induced PD, and POMC gene may play a role. And POMC gene may be the direct target of DZF to regulate microglial phenotype and neuroinflammation.

Pro-opiomelanocortin (POMC) is an opioid precursor, which exists in the pituitary gland, central nervous system, pancreas and other tissues. It participates in regulating the body's energy metabolism and appetite. In addition, it was 
reported that dopamine could inhibit the synthesis of POMC. ${ }^{62}$ It has been reported that the level of POMC derivative $\beta$-endorphin in the cerebrospinal fluid of patients with $\mathrm{PD}$ is reduced, D2 dopamine receptors regulate the production of POMC, and the impaired POMC processing in PD may be related to the activity of $\mathrm{D} 2$ dopamine receptors. ${ }^{63,64}$ In addition, Ropelle and Shi et al have reported that POMC is affected by IL-6 and is a downstream target of NF- $\mathrm{kB} .{ }^{65-67}$ Even the expression of POMC mRNA in LPS-treated rats is elevated. ${ }^{68}$ Furthermore, the endogenous peptide $\alpha$-MSH, which is derived from the POMC, also has antiinflammatory and neuroprotective effects. ${ }^{69-71}$ It can regulate microglia inflammation, and participate in the NF- $\mathrm{KB}$ pathway. ${ }^{72}$ Based on the above literatures and our results, it is shown that POMC plays an important role in the inflammatory response of $\mathrm{PD}$. We therefore speculate that POMC may be a potential therapeutic target for PD. Simultaneously, we were fortunate to have demonstrated a regulation of POMC by DZF. It is important to note, however, that our current research has some limitations. Naturally, to confirm the correlation, further confirmation would be required. For instance, through application of POMC gene knockdown or knockout models.

\section{Conclusions}

In conclusion, we have confirmed that DZF can improve Parkinson's disease-like symptoms. In addition, we explored a new target in PD, POMC. DZF can regulate neuroinflammation by targeting the POMC gene and reduce the death of dopaminergic neurons, thereby improving the motor function of parkinsonian mice.

\section{Acknowledgments}

This study was supported by the National Natural Science Foundation of China (81703827).

\section{Author Contributions}

All authors made substantial contributions to conception and design, acquisition of data, or analysis and interpretation of data; took part in drafting the article or revising it critically for important intellectual content; agreed to submit to the current journal; gave final approval for the version to be published; and agreed to be accountable for all aspects of the work.

\section{Disclosure}

The authors report no conflicts of interest.

\section{References}

1. Tysnes OB, Storstein A. Epidemiology of Parkinson's disease. J Neural Transm. 2017;124(8):901-905. doi:10.1007/s00702-0171686-y

2. Fabbri M, Reimão S, Carvalho M, et al. Substantia nigra neuromelanin as an imaging biomarker of disease progression in Parkinson's disease. J Parkinsons Dis. 2017;7(3):491-501. doi:10.3233/JPD171135

3. Dickson DW. Neuropathology of Parkinson disease. Parkinsonism Relat Disord. 2018;46(Suppl 1):S30-S33. doi:10.1016/j. parkreldis.2017.07.033

4. Stojkovska I, Wagner BM, Morrison BE. Parkinson's disease and enhanced inflammatory response. Exp Biol Med. 2015;240 (11):1387-1395. doi:10.1177/1535370215576313

5. Collins LM, Toulouse A, Connor TJ, Nolan YM. Contributions of central and systemic inflammation to the pathophysiology of Parkinson's disease. Neuropharmacology. 2012;62(7):2154-2168. doi:10.1016/j.neuropharm.2012.01.028

6. Elzbieta J, Laura B, Carta AR, Phagocytosis M. Its regulation: a therapeutic target in Parkinson's disease? Front Mol Neurosci. 2018;11:1-7. doi:10.3389/fnmol.2018.00144

7. Green DR, Oguin TH, Martinez J. The clearance of dying cells: table for two. Cell Death Differ. 2016;23(6):915-926. doi:10.1038/ cdd.2015.172

8. Nau R, Ribes S, Djukic M, Eiffert H. Strategies to increase the activity of microglia as efficient protectors of the brain against infections. Front Cell Neurosci. 2014;8:138. doi:10.3389/ fncel.2014.00138

9. Maatouk L, Compagnion AC, Sauvage MC, et al. TLR9 activation via microglial glucocorticoid receptors contributes to degeneration of midbrain dopamine neurons. Nat Commun. 2018;9(1):2450. doi:10.1038/s41467-018-04569-y

10. Rees K, Stowe R, Patel S, et al. Non-steroidal anti-inflammatory drugs as disease-modifying agents for Parkinson's disease: evidence from observational studies. Cochrane Database Syst Rev. 2011;11: CD008454. doi:10.1002/14651858

11. Yacoubian TA, Standaert DG. Targets for neuroprotection in Parkinson's disease. Biochim Biophys Acta. 2009;1792(7):676-687. doi:10.1016/j.bbadis.2008.09.009

12. Ren L, Yi J, Yang J, Li P, Cheng X, Mao P. Nonsteroidal anti-inflammatory drugs use and risk of Parkinson disease: a dose-response meta-analysis. Medicine. 2018;97(37):e12172. doi:10.1097/MD.000000000012172

13. Poly TN, Islam MMR, Yang HC, Li YJ. Non-steroidal antiinflammatory drugs and risk of Parkinson's disease in the elderly population: a meta-analysis. Eur J Clin Pharmacol. 2019;75 (1):99-108. doi:10.1007/s00228-018-2561-y

14. Cayero-Otero MD, Espinosa-Oliva AM, Herrera AJ, et al. Potential use of nanomedicine for the anti-inflammatory treatment of neurodegenerative diseases. Curr Pharm Des. 2018;24(14):1589-1616. doi:10.2174/1381612824666180403113015

15. Mir RH, Shah AJ, Mohi-Ud-Din R, et al. Natural anti-inflammatory compounds as drug candidates in Alzheimer's disease. Curr Med Chem. 2020;30. doi:10.2174/0929867327666200730213215

16. Yao YY, Ling EA, Lu D. Microglia mediated neuroinflammation signaling regulation and therapeutic considerations with special reference to some natural compounds. Histol Histopathol. 2020;35 (11):1229-1250. doi:10.14670/HH-18-239

17. Wu HZ, Fang ZQ, Cheng PJ. The theory of Yin and Yang. U Chi L Rev. 2013;1:33-46. doi:10.1142/9781938134296_0003

18. Fan S, Yin Q, Li D, et al. Anti-neuroinflammatory effects of Eucommia ulmoides Oliv. In a Parkinson's mouse model through the regulation of p38/JNK-Fosl2 gene expression. J Ethnopharmacol. 2020;260:113016. doi:10.1016/j.jep.2020.113016 
19. National Pharmacopoeia Commission. The Pharmacopoeia of the People's Republic of China (Part I). Beijing: China Medical Science and Technology Press; 2020.

20. García E, Villeda-Hernández J, Pedraza-Chaverrí J, Maldonado PD, Santamaría A. S-allylcysteine reduces the MPTP-induced striatal cell damage via inhibition of pro-inflammatory cytokine tumor necrosis factor- $\alpha$ and inducible nitric oxide synthase expressions in mice. Phytomedicine. 2010;18:65-73. doi:10.1016/j.phymed.2010.04.004

21. Huang D, Wang Z, Tong J, et al. Long-term changes in the nigrostriatal pathway in the MPTP mouse model of Parkinson's disease. Neuroscience. 2018;369:303-313. doi:10.1016/j. neuroscience.2017.11.041

22. Wang CT, Mao CJ, Zhang XQ, et al. Attenuation of hyperalgesia responses via the modulation of 5-hydroxytryptamine signalings in the rostral ventromedial medulla and spinal cord in a 6-hydroxydopamine-induced rat model of Parkinson's disease. Mol Pain. 2017;13:1744806917691525. doi:10.1177/ 1744806917691525

23. Luo FC, Wang SD, Qi L, Song JY, Lv T, Bai J. Protective effect of panaxatriol saponins extracted from Panax notoginseng against MPTP-induced neurotoxicity in vivo. J Ethnopharmacol. 2011;133 (2):448-453. doi:10.1016/j.jep.2010.10.017

24. Wang W, Shi L, Xie Y, et al. SP600125, a new JNK inhibitor, protects dopaminergic neurons in the MPTP model of Parkinson's disease. Neurosci Res. 2004;48(2):195-202. doi:10.1016/j.neures.2003.10.012

25. Perez-Pardo P, Dodiya HB, Engen PA, et al. Role of TLR4 in the gutbrain axis in Parkinson's disease: a translational study from men to mice. Gut. 2019;68(5):829-843. doi:10.1136/gutjnl-2018-316844

26. Livak KJ, Schmittgen TD. Analysis of relative gene expression data using real-time quantitative PCR and the 2(-Delta Delta $\mathrm{C}(\mathrm{T})$ ) method. Methods. 2001;25(4):402-408. doi:10.1006/meth.2001.1262

27. Szklarczyk D, Gable AL, Lyon D, et al. STRING v11: protein-protein association networks with increased coverage, supporting functional discovery in genome-wide experimental datasets. Nucleic Acids Res. 2019;47(D1):D607-D613. doi:10.1093/nar/gky1131

28. Cebrián C, Zucca FA, Mauri P, et al. MHC-I expression renders catecholaminergic neurons susceptible to T-cell-mediated degeneration. Nat Commun. 2014;5:3633. doi:10.1038/ncomms4633

29. Yoon KW, Yang HS, Kim YM, et al. CIB1 protects against MPTP-induced neurotoxicity through inhibiting ASK1. Sci Rep 2017;7(1):12178. doi:10.1038/s41598-017-12379-3

30. Tritsch NX, Sabatini BL. Dopaminergic modulation of synaptic transmission in cortex and striatum. Neuron. 2012;76(1):33-50. doi:10.1016/j.neuron.2012.09.023

31. Franceschelli S, Lanuti P, Ferrone A, et al. Modulation of apoptotic cell death and neuroprotective effects of glutathione-1-dopa codrug against H2O2-induced cellular toxicity. Antioxidants. 2019;8(8):319. doi:10.3390/antiox8080319

32. Butkovich LM, Houser MC, Tansey MG. $\alpha$-synuclein and noradrenergic modulation of immune cells in Parkinson's disease pathogenesis. Front Neurosci. 2018;12:626. doi:10.3389/fnins.2018.00626

33. Neumann H, Kotter MR, Franklin RJ. Debris clearance by microglia: an essential link between degeneration and regeneration. Brain. 2009;132(Pt 2):288-295. doi:10.1093/brain/awn109

34. Imamura K, Hishikawa N, Sawada M, Nagatsu T, Yoshida M, Hashizume Y. Distribution of major histocompatibility complex class II-positive microglia and cytokine profile of Parkinson's disease brains. Acta Neuropathol. 2003;106(6):518-526. doi:10.1007/ s00401-003-0766-2

35. Hirsch EC, Hunot S. Neuroinflammation in Parkinson's disease: a target for neuroprotection? Lancet Neurol. 2009;8(4):382-397. doi:10.1016/S1474-4422(09)70062-6

36. Halliday GM, Stevens CH. Glia: initiators and progressors of pathology in Parkinson's disease. Mov Disord. 2011;26(1):6-17. doi: $10.1002 / \mathrm{mds} .23455$
37. Herrero MT, Estrada C, Maatouk L, Vyas S. Inflammation in Parkinson's disease: role of glucocorticoids. Front Neuroanat. 2015;9:32. doi:10.3389/fnana.2015.00032

38. Lawson LJ, Perry VH, Dri P, Gordon S. Heterogeneity in the distribution and morphology of microglia in the normal adult mouse brain. Neuroscience. 1990;39(1):151-170. doi:10.1016/03064522(90)90229-w

39. Kim WG, Mohney RP, Wilson B, Jeohn GH, Liu B, Hong JS. Regional difference in susceptibility to lipopolysaccharide-induced neurotoxicity in the rat brain: role of microglia. $J$ Neurosci. 2000;20(16):6309-6316. doi:10.1523/JNEUROSCI.20-1606309.2000

40. Barcia C, Ros CM, Ros-Bernal F, et al. Persistent phagocytic characteristics of microglia in the substantia nigra of long-term Parkinsonian macaques. J Neuroimmunol. 2013;261(1-2):60-66. doi:10.1016/j.jneuroim.2013.05.001

41. Mass E, Jacome-Galarza CE, Blank T, et al. A somatic mutation in erythro-myeloid progenitors causes neurodegenerative disease. Nature. 2017;549(7672):389-393. doi:10.1038/nature23672

42. Zhao X, Liao Y, Morgan S, et al. Noninflammatory changes of microglia are sufficient to cause epilepsy. Cell Rep. 2018;22 (8):2080-2093. doi:10.1016/j.celrep.2018.02.004

43. Wu J, Ding DH, Li QQ, Wang XY, Sun YY, Li LJ. Lipoxin A4 regulates lipopolysaccharide-induced BV2 microglial activation and differentiation via the notch signaling pathway. Front Cell Neurosci. 2019;13:19. doi:10.3389/fncel.2019.00019

44. Prinz M, Priller J. Microglia and brain macrophages in the molecular age: from origin to neuropsychiatric disease. Nat Rev Neurosci. 2014;15(5):300-312. doi:10.1038/nrn3722

45. Vezzani A, Aronica E, Mazarati A, Pittman QJ. Epilepsy and brain inflammation. Exp Neurol. 2013;244:11-21. doi:10.1016/j. expneurol.2011.09.033

46. Michels M, Abatti MR, Ávila P, et al. Characterization and modulation of microglial phenotypes in an animal model of severe sepsis. J Cell Mol Med. 2020;24(1):88-97. doi:10.1111/jcmm.14606

47. Kitagawa Y, Nakaso K, Horikoshi Y, et al. System xc- in microglia is a novel therapeutic target for post-septic neurological and psychiatric illness. Sci Rep. 2019;9(1):7562. doi:10.1038/s41598-019-44006-8

48. Lan X, Han X, Li Q, Yang QW, Wang J. Modulators of microglial activation and polarization after intracerebral haemorrhage. Nat Rev Neurol. 2017;13(7):420-433. doi:10.1038/nrneurol.2017.69

49. Hu X, Leak RK, Shi Y, et al. Microglial and macrophage polarization —new prospects for brain repair. Nat Rev Neurol. 2015;11(1):56-64. doi:10.1038/nrneurol.2014.207

50. Dai D, Yuan J, Wang Y, Xu J, Mao C, Xiao XY. Peli1 controls the survival of dopaminergic neurons through modulating microglia-mediated neuroinflammation. Sci Rep. 2019;9(1):8034. doi:10.1038/s41598-019-44573-w

51. Brown GC. Mechanisms of inflammatory neurodegeneration: iNOS and NADPH oxidase. Biochem Soc Trans. 2007;35(Pt 5):1119-1121. doi:10.1042/BST0351119

52. Gao HM, Liu B, Zhang W, Hong JS. Critical role of microglial NADPH oxidase-derived free radicals in the in vitro MPTP model of Parkinson's disease. FASEB J. 2003;17(13):1954-1956. doi:10.1096/fj.03-0109fje

53. Lecca D, Janda E, Mulas G, et al. Boosting phagocytosis and antiinflammatory phenotype in microglia mediates neuroprotection by PPAR $\gamma$ agonist MDG548 in Parkinson's disease models. $\mathrm{Br}$ J Pharmacol. 2018;175(16):3298-3314. doi:10.1111/bph.14214

54. Block ML, Zecca L, Hong JS. Microglia-mediated neurotoxicity: uncovering the molecular mechanisms. Nat Rev Neurosci. 2007;8 (1):57-69. doi:10.1038/nrn2038

55. Rojanathammanee L, Murphy EJ, Combs CK. Expression of mutant alpha-synuclein modulates microglial phenotype in vitro. J Neuroinflammation. 2011;8:44. doi:10.1186/1742-2094-8-44 
56. Nikolakopoulou AM, Dutta R, Chen Z, Miller RH, Trapp BD. Activated microglia enhance neurogenesis via trypsinogen secretion. Proc Natl Acad Sci U S A. 2013;110(21):8714-8719. doi:10.1073/ pnas. 1218856110

57. Truettner JS, Bramlett HM, Dietrich WD. Posttraumatic therapeutic hypothermia alters microglial and macrophage polarization toward a beneficial phenotype. J Cereb Blood Flow Metab. 2017;37 (8):2952-2962. doi:10.1177/0271678X16680003

58. Butovsky O, Talpalar AE, Ben-Yaakov K, Schwartz M. Activation of microglia by aggregated beta-amyloid or lipopolysaccharide impairs MHC-II expression and renders them cytotoxic whereas IFN-gamma and IL-4 render them protective. Mol Cell Neurosci. 2005;29 (3):381-393. doi:10.1016/j.mcn.2005.03.005

59. Zhou X, Spittau B, Krieglstein K. TGF $\beta$ signalling plays an important role in IL4-induced alternative activation of microglia. $J$ Neuroinflammation. 2012;9:210. doi:10.1186/1742-2094-9-210

60. Kroner A, Greenhalgh AD, Zarruk JG, et al. TNF and increased intracellular iron alter macrophage polarization to a detrimental M1 phenotype in the injured spinal cord. Neuron. 2014;83(5):1098-1116. doi:10.1016/j.neuron.2014.07.027

61. Benson MJ, Manzanero S, Borges K. Complex alterations in microglial M1/M2 markers during the development of epilepsy in two mouse models. Epilepsia. 2015;56(6):895-905. doi:10.1111/ epi. 12960

62. Zhang X, van den Pol AN. Hypothalamic arcuate nucleus tyrosine hydroxylase neurons play orexigenic role in energy homeostasis. Nat Neurosci. 2016;19(10):1341-1347. doi:10.1038/nn.4372

63. Nappi G, Petraglia F, Martignoni E, et al. Beta-Endorphin cerebrospinal fluid decrease in untreated parkinsonian patients. Neurology. 1985;35(9):1371-1374. doi:10.1212/wnl.35.9.1371

64. Sandyk R. Pro-opiomelanocortin (POMC) processing in Parkinson's disease. Int $J$ Neurosci. 1989;46(3-4):201-204. doi:10.3109/ 00207458908986258
65. Ropelle ER, Flores MB, Cintra DE, et al. IL-6 and IL-10 antiinflammatory activity links exercise to hypothalamic insulin and leptin sensitivity through IKK $\beta$ and ER stress inhibition. PLoS Biol. 2010;8(8):e1000465. doi:10.1371/journal.pbio. 1000465

66. Shi X, Wang X, Li Q, et al. Nuclear factor $\kappa B(N F-\kappa B)$ suppresses food intake and energy expenditure in mice by directly activating the Pomcpromoter. Diabetologia. 2013;56(4):925-936. doi:10.1007/ s00125-013-2831-2

67. Pereda MP, Lohrer P, Kovalovsky D, et al. Interleukin-6 is inhibited by glucocorticoids and stimulates ACTH secretion and POMC expression in human corticotroph pituitary adenomas. Exp Clin Endocrinol Diabetes. 2000;108(3):202-207. doi:10.1055/s-20007887

68. Sergeyev V, Broberger C, Hökfelt T. Effect of LPS administration on the expression of POMC, NPY, galanin, CART and MCH mRNAs in the rat hypothalamus. Brain Res Mol Brain Res. 2001;90(2):93-100. doi:10.1016/s0169-328x(01)00088-2

69. Gantz I, Fong TM. The melanocortin system. Am J Physiol Endocrinol Metab. 2003;284(3):E468. doi:10.1152/ ajpendo.00434.2002

70. Catania A, Lonati C, Sordi A, et al. The melanocortin system in control of inflammation. Thescientificworldjournal. 2014;10(1):1840. doi: $10.1100 /$ tsw. 2010.173

71. Wang M, Zhi D, Wang $H$, et al. TAT-HSA- $\alpha-M S H$ fusion protein with extended half-life inhibits tumor necrosis factor- $\alpha$ in brain inflammation of mice. Appl Microbiol Biotechnol. 2016;100 (12):5353-5361. doi:10.1007/s00253-015-7251-4

72. Carniglia L, Ramírez D, Durand D, et al. Neuropeptides and microglial activation in inflammation, pain, and neurodegenerative diseases. Mediators Inflamm. 2017;2017:5048616. doi:10.1155/ $2017 / 5048616$
Journal of Inflammation Research

\section{Publish your work in this journal}

The Journal of Inflammation Research is an international, peerreviewed open-access journal that welcomes laboratory and clinical findings on the molecular basis, cell biology and pharmacology of inflammation including original research, reviews, symposium reports, hypothesis formation and commentaries on: acute/chronic inflammation; mediators of inflammation; cellular processes; molecular

\section{Dovepress}

mechanisms; pharmacology and novel anti-inflammatory drugs; clinical conditions involving inflammation. The manuscript management system is completely online and includes a very quick and fair peerreview system. Visit http://www.dovepress.com/testimonials.php to read real quotes from published authors. 